\title{
Two Decades (1993-2012) of Adult Intensive Care Unit Design:
}

\section{A Comparative Study of the Physical Design Features of the Best-Practice Examples}

\author{
Author: \\ Mahbub Rashid, PhD, RA \\ Professor of Architecture, University of Kansas \\ 1465 Jayhawk Boulevard, Lawrence, Kansas 66045 \\ E-mail: mrashid@ku.edu
}

Acknowledgement:

The study was partly funded by the General Research Fund of the University of Kansas. 


\title{
Two Decades (1993-2012) of Adult Intensive Care Unit Design:
}

\section{A Comparative Study of the Physical Design Features of the Best-Practice Examples}

\begin{abstract}
In 2006, Critical Care Nursing Quarterly published a study of the physical design features of a set of best-practice example adult intensive care units (ICUs) [1]. These adult ICUs were awarded between 1993 and 2003 by the Society of Critical Care Medicine (SCCM), the American Association of Critical Care Nurses (AACCN), and the American Institute of Architects/Academy of Architecture for Health (AIA/AAH) for their efforts to promote the critical care unit environment through design. Since 2003 several more adult ICUs were also awarded by the same organizations for similar efforts. The present study includes these newer ICUs with those of the previous study to cover a period of two decades from 1993 to 2012.
\end{abstract}

Like the 2006 study, the present study conducts a systematic content analysis of the materials submitted by the award-winning adult ICUs. Based on the analysis, the study compares the 1993-2002 and 20032012 adult ICUs in relation to construction type, unit specialty, unit layout, unit size, patient room size and design, support and service area layout, and family space design. The study also compares its findings with the 2010 Guidelines for Design and Construction of HealthCare Facilities [2] of the Facility Guidelines Institute (FGI) and the 2012Guidelines for Intensive Care Unit Design [3] of the Society of Critical Care Medicine (SCCCM).

The study indicates that the award-winning ICUs of both the decades used several design features that were associated with positive outcomes in research studies. The study also indicates that the awardwinning ICUs of the second decade used more evidence-based design features than those of the first decades. In most cases, these ICUs exceeded the requirements of the FGI Guidelines to meet those of the SCCM Guidelines. Yet, the award-winning ICUs of both the decades also used several features that had very little or no supporting research evidence. Since they all were able to create an optimal critical care environment for which they were awarded, having knowledge of the physical design of these awardwinning ICUs may help design better ICUs.

Key words: best practices, design features, unit design, unit layout, patient room, support and service areas, staff work area, service area, family area 


\section{INTRODUCTION}

Physical design is a key part of the care environment in intensive care units (ICUs). It can affect patient care outcomes, as well as patient stress, satisfaction, dignity, privacy, confidentiality and safety. It can also affect staff outcomes including satisfaction, safety, stress, and performance. Additionally, it can affect patient family satisfaction and stress. Further, the physical design of ICUs can affect unit-related outcomes [for a review of the related literature, refer to 3-9].

Recognizing the importance of ICU design, since 1992 the Society of Critical Care Medicine (SCCM), the American Association of Critical Care Nurses (AACCN), and the American Institute of Architects/Academy of Architecture for Health (AIA/AAH) have been co-sponsoring an annual ICU design competition. The competition recognizes ICUs that make exceptional efforts to promote healing of the critically ill and injured patients through the design of the critical care unit environment. Until now, the competition has been open to all ICUs regardless of medical specialty or subspecialty [for more on the competition process, refer to 10].

For competition purposes, all entries submit a fact sheet with the background information that include, among other things, the type and size of the hospital that houses the unit, the type and size of the unit, the type of design, the size of a typical patient room, the type of power/equipment mounting in the patient room, the date of completion and occupation, the type of construction, and the budget. All entries also submit a video footage with audio narrative, a brief written description, and one or more drawings of the floor plan and the building block plan. The materials submitted by the winning entries have been compiled and published by the above organizations for the benefit of all [for example, refer to 11].

Since the winning entries of the SCCM, AACCN, \& AIA/AAH competition represent some of the bestpractice example ICUs, in 2006 Critical Care Nursing Quarterly published a study of the physical design features of the winning adult ICUs between 1993 and 2003 [1]. In reporting its findings, the 2006 study focused on issues related to overall design, patient room design, support and service area design, and family area design in these adult ICUs.

Concerning the overall ICU design issues, the 2006 study made the following observations: 1) a significant number of winning entries were renovated units, even though renovation posed greater threat to health and safety; 2) most winning entries were mixed-specialty units, even though these units might have more problems to solve than single specialty or subspecialty ICUs; 3) the average number of patient beds in these units was 22, a number much larger than that recommended by the 1995 SCCM Guidelines [12] or by ICU experts [13-15]; 4) the average gross area per patient bed varied significantly among the 
winning entries; 5) the most popular type of unit layout was the racetrack type layout, even though there was no empirical study supporting its advantages over the other layout types; and 6) the geometry and amount of circulation spaces varied widely in these ICUs, providing no benchmark for an efficient and socially-favorable ICU design.

Concerning the patient room design issues, the 2006 study made the following observations: 1) the average size of a patient room in the winning entries was about 250 square feet, as per the 1995 SCCM Guidelines[12] ; 2) most patient rooms had free-standing beds with medical utilities provided by power columns;3) most patient rooms in most units were private rooms; 4) most ICUs had one or more isolation rooms; 5) most patient rooms had natural light and views; 6) most patient rooms had glass breakaway doors to increase patient visibility and to facilitate patient care and transfer; 7) most units had private toilets and/or waste disposal facilities within patient rooms; 8) most patient rooms had handwashing sinks as an important infection prevention intervention; and 9) the majority of these sinks were located at the near-end of the side wall for ease of use by ICU staff.

Concerning support and service area design in ICUs, the 2006 study made the following observations: 1) in most cases ICUs had staff work areas composed of several observation stations; 2) in most ICUs the service areas were located centrally; 3 ) in most ICUs charting was done in or near the patient room to reduce nurses' time and energy spent on this function; and 4) in each ICU a staff lounge area was provided to help physical and mental restoration of ICU staff.

Concerning family area design in ICUs, the 2006 study made the following observations: 1) all winning entries had family areas but most units did not have a designated family space in the patient room; 2) in most cases family space was located outside the unit; and 3) each unit had one or more family consultation rooms.

The present study reports the design features of the award-winning adult ICUs of the last two decades from 1993 to 2012 to find out if the 1993-2002 adult ICUs are any different from the 2003-2012 adult ICUs. The study compares its findings with the Guidelines for Design and Construction of HealthCare Facilities [2] of the Facility Guidelines Institute (FGI) and the Guidelines for Intensive Care Unit Design [3]. FGI administers the process and establishes rules to promote fairness in the development of consensus concerning the minimal guidelines for health care facilities design. Independently, FGI does not test, evaluate, or verify the accuracy of any information or the soundness of any judgments or advice contained in its guidelines. Though the FGI Guidelines are not intended to restrict innovations and improvements in design or construction techniques, many states adopt the FGI Guidelines as regulatory documents. In contrast, the SCCM Guidelines are not regulatory documents. They are developed by a 
group of multidisciplinary professionals, designers, and architects with expertise in critical care, under the direction of the American College of Critical Care Medicine. These Guidelines contain 'recommendations for a more optimal approach for a healing environment' [3:1586]. Therefore, it should be interesting to see to what extent the award-winning adult ICUs go beyond the FGI Guidelines to meet the recommendations of the SCCM Guidelines.

\section{MATERIALS AND METHODS}

Like the 2006 study, the present study was based on a systematic content analysis of the materials submitted by the award-winning ICUs of the last two decades. These materials were jointly published in a CD and a DVD by SCCM, AACCN, and AIA/AAH in 2012 [11]. As noted above, the materials included a fact sheet, a video footage with audio narrative, a brief written description, and one or more drawings of the layout of all the award-winning ICUs between 1993 and 2012. A few of the award-winning adult ICUs were excluded from the study, because the published materials did not contain legible drawings with enough design information. All the award-winning neonatal and pediatric ICUs were also excluded from the study. Additionally, one award-winning adult ICU from the Netherlands was also excluded from the study, because it had several design features not commonly found in this country.

Altogether, the study included 25 award-winning adult ICUs built between 1993 and 2012. Out of the 25 ICUs, 15 ICUs represented the decade from 1993 to 2002 and 10 ICUs the decade from 2003 to 2012. In addition to the exclusion criteria above, these unequal numbers can also be explained by the fact that the numbers of winning ICUs in a year were sometimes more than one, and that some of the winning entries were not always adult ICUs [11].

Like the 2006 study, the present study also focused on issues related to overall design, patient room design, support and service area design, and family area design in these adult ICUs, and used the same definitions of the 2006 paper. Some of the overall design issues discussed in the 2006 paper included unit construction types, unit functional types or specialty, unit layout types, and unit size. Different categories of unit construction types included in the study were new construction, renovation, and part-new and partrenovation. Two categories of unit specialty types included in the study were single- and mixed-specialty or -subspecialty. Different categories of unit layout types included in the study were racetrack type, single-corridor type, open-plan type, radial type, and other (some combination or modifications of the former types). 
Some of the patient room design issues discussed in the 2006 paper included the size of a typical patient room, the configuration of life support systems and medical utilities, the number of private and isolation rooms in the unit, patient room door, patient room toilet, location of hand-washing sinks inside the patient room, and access to natural light and outside view.

The support areas in the 2006 paper included designated spaces or areas in which staff members perform auxiliary functions related to patient care. The basic component of support areas include staff work areas composed of centralized nurse station, substations, observation stations, and/or charting area. Other support areas were administrative offices, conference spaces, on-call rooms, staff lounge, restrooms and lockers; and pharmacy, laboratory, and imaging when available. These areas also included any other spaces used for one or more staff activities and/or functions. Concerning support areas, the 2006 paper put the most emphasis on staff work area layout.

Service areas in the 2006 paper included clean utility room, soiled utility room, patient nourishment space, med supply room, housekeeping, and any other storage spaces. In the 2006 paper, design features of any individual service areas were not discussed separately but were mentioned in relation to the layout of service areas.

Circulation spaces in the 2006 paper included internal hallways, corridors, and/or aisles used by all ICU users - patients, ICU staff, and visitors. They did not include private movement areas within any welldefined areas such as the nursing station and the patient room. They also did not include elevator cores, fire-stairs, and open lobby areas if identified as waiting spaces.

Finally, family areas in the 2006 paper included any spaces that provided support for patient families and visitors. These spaces included, but were not limited to, family waiting area or lounge, consultation rooms, family nourishment space, sleeping rooms, meditation spaces, and spaces with such amenities as lockers, washer and dryers, and bathrooms with shower. Concerning family areas, the 2006 paper put the most emphasis on the location of family waiting spaces.

The 2006 paper used the 2005 SCCM, AACCN, and AIA/AAH publications [16] for its purposes. These publications did not include sufficient information on several environmental systems and technological features. When included, the information on these systems and features was presented unevenly. Therefore, important technological features that were not discussed in the 2006 paper included information management and communication systems, medical technology and equipment, and supply and waste management systems, even though developments related to these systems could eventually change the critical care practice as we know it today [17]. Environmental systems (heating, ventilation, 
and air conditioning), alarm systems, security and access control systems, lighting systems, furniture and finishes were also not included in the 2006 study. Since the 2012 publications [11] also have some of the limitations, this present study does not include any in-depth analysis of the technological features and systems of the award-winning ICUs. This is also in line with the main purpose of the paper, which is to look at some of the physical design features of the award-winning adult ICUs.

\section{OVERALL DESIGN ISSUES}

\section{Unit construction type}

Changes in technology, patient demographics or disease patterns, performance standards, and care delivery models are among the important reasons for building new ICUs or renovating the old ones. Building new ICUs may be costlier, but renovating the old ones is never easy. Renovations often put patients and staff in harm's way that can be avoided in a new construction. In the absence of appropriate protection provisions, renovations may cause disruption in patient care and building services. They may expose patients and staff to disruptive noise, harmful allergens, and carcinogenic materials (particularly when hospital facilities are old enough to contain asbestos). During renovation, vulnerable patients are often moved to temporary locations that lack optimal care environments. [For examples of studies on safety and construction in hospitals, refer to 18-22.]

Recognizing many negative issues related to renovation, the FGI Guidelines states:

Renovation of a unit shall include phasing to minimize disruption of existing patient services. Phasing plans shall include considerations of noise and vibration control that result from construction activities. During construction renovation areas shall also be isolated from occupied areas based on infection control risk assessment (ICRA). Existing air quality requirements and other utility requirements for occupied areas (for example, domestic water, treated water, wastewater, pneumatic tube, pneumatic controls, and medical gases/vacuum) shall be maintained during any renovation. [2:32]

The findings of the study show that between 1993 and 2002 renovation was more frequent than new construction, whereas between 2003 and 2012 new construction was more frequent than renovation among the award-winning ICUs. Among the 1993-2002 ICUs, 46.67\% were the renovated units, 40\% were the newly built units, and $13.33 \%$ were the partly-renovated and partly-new units. In contrast, 
among the 2003-2012 ICUs 40\% were the renovated units, 60\% were the newly built units, and $0 \%$ was the partly-renovated and partly-new units (Figure 1).

Therefore, the findings of the study indicate a positive trend among the award-winning ICUs since renovating ICUs can often become more hazardous and difficult than building new ICUs. It is hard to say if the findings were a mere coincidence. It is quite possible that in some of the years no new construction or renovation entries were submitted. Nonetheless, it would be interesting if the findings indicate a more general trend in ICU construction. It would also be interesting if the findings indicate an increasing awareness regarding the safety issues associated with ICU construction around the country.

\section{Unit functional type or specialty}

Since types and severity of illnesses vary significantly among patients, no one critical care environment can support optimal care for all patients. Some patients are more unstable than others, thus requiring more monitoring. Some patients need more interventions than others, thus requiring more equipment and facilities for these interventions in the unit or in the patient room. Some patients stay longer than others, thus requiring more family spaces. Some patients are heavier than others, thus requiring more space and people for care. Some patients are more infectious than others, thus requiring more environmental protection. The list is almost without end. Therefore, there is a need for specialty or subspecialty ICUs that serve similar patients to the extent possible. In mixed-specialty ICUs, managing and staffing patients may become difficult. They may also have too many or too few features for some patients. Therefore, single-specialty or -subspecialty ICUs make more sense in terms of safety, efficiency, and effectiveness of critical care, when resources are available in the hospital to support these units.

Among the 1993-2002 ICUs 40\% were the single-specialty units and $60 \%$ were the mixed-specialty units. In contrast, among the 2003-2012 60\% were the single-specialty units and $40 \%$ were the mixedspecialty units (Figure 2). These findings indicate that in the first decade more units served mixedspecialty than single-specialty, whereas in the second decade more units served single-specialty than mixed-specialty. Again, the findings indicate a positive trend among the award-winning ICUs in light of the observation that a mixed-specialty unit may be more difficult to manage and staff than a singlespecialty unit [for example, refer to 23]. 


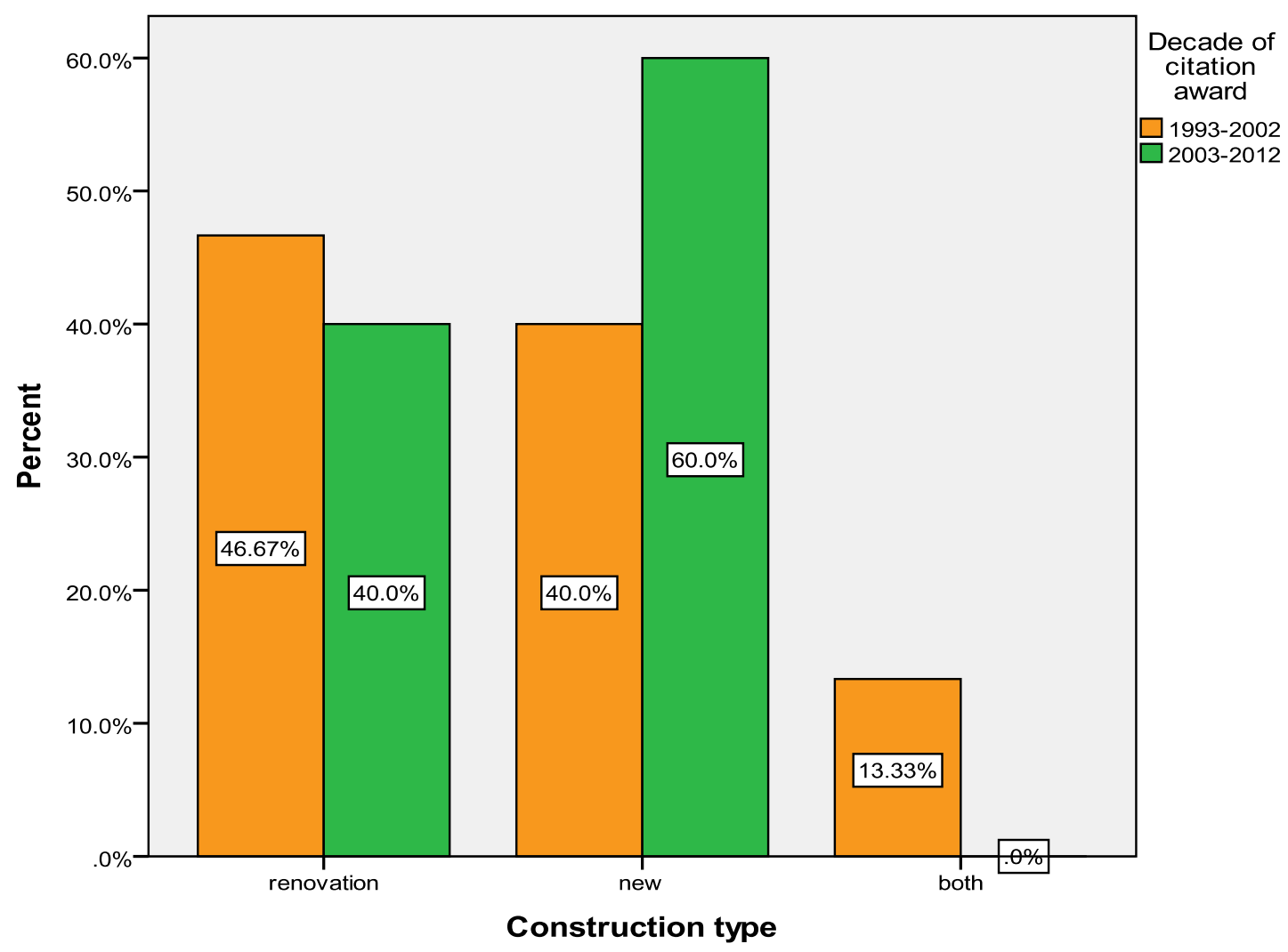

Figure 1: Different types of construction by decade.

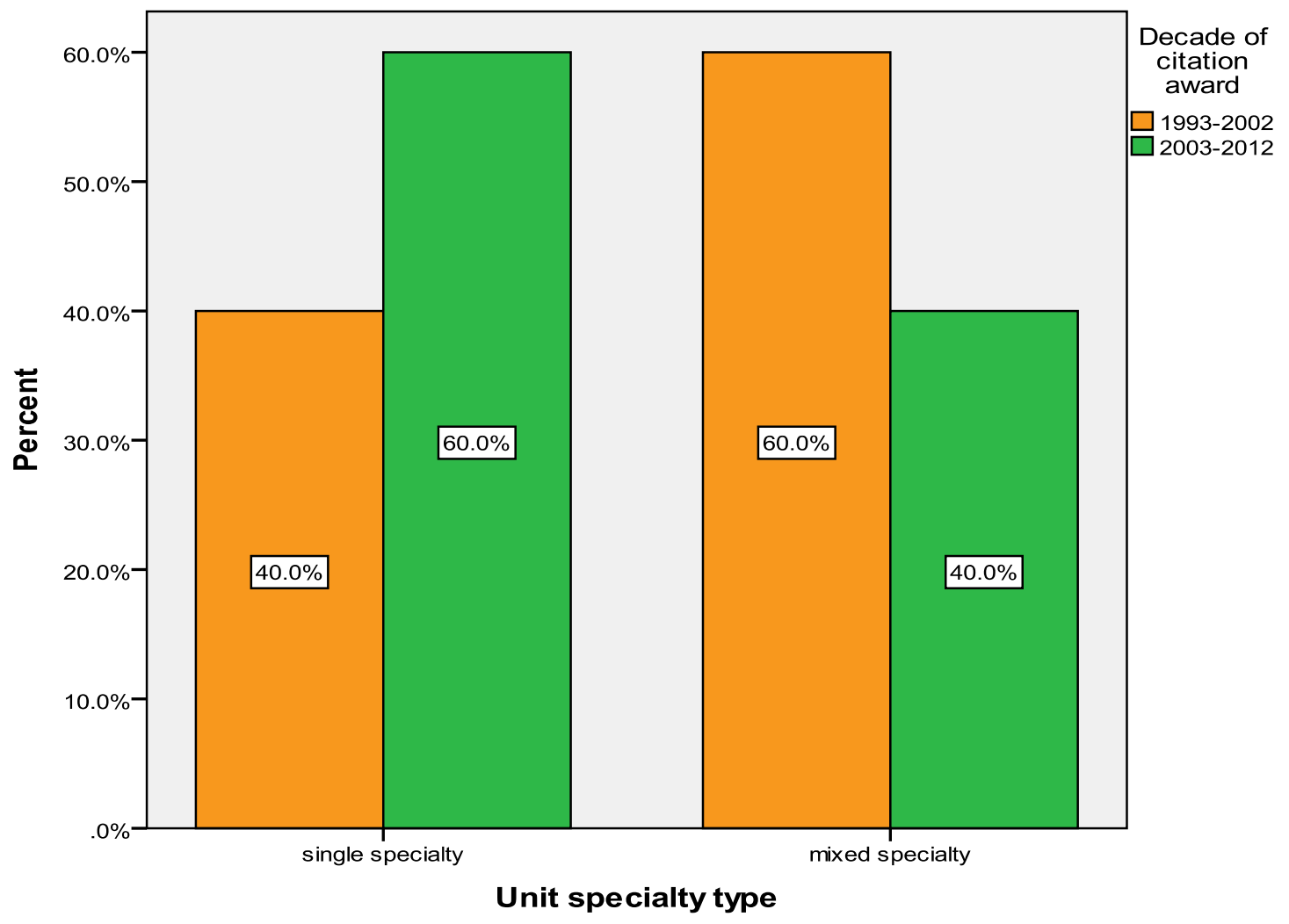

Figure 2: Single- and mixed-specialty ICUs by decade. 


\section{Unit layout}

ICUs, like any other hospital inpatient units, can be designed to have different layouts. Among the more commonly used layouts are racetrack layout, single- or double-corridor layout, open-plan layout, radial layout and some combinations or variations of these layouts. Several of these common unit layouts are shown in Figure 3 [originally published in 24]. Even though some studies show that radial units perform better than single- and/or double-corridor units due to better visibility and shorter walking [for example, refer to 25-27], systematic studies comparing all different types of unit layout in terms of systems, group and person-related outcomes are still missing.

This study finds that, among the 1993-2002 ICUs, 66.67\% were the racetrack type units; $13.33 \%$ were the open-plan layout units; $0 \%$ was the corridor type units; 6.67\% were the radial layout units; and 13.33\% were the mixed layout units. In contrast, among the 2003-2012 ICUs, 80\% were the racetrack type units; $10 \%$ were the open layout units; $10 \%$ were the corridor type units; $0 \%$ was the radial layout units; and 0\% was the mixed layout units (Figure 4). These findings indicate that there were more variations in unit layout types in the first decade than there were in the second decade. The findings also indicate that the racetrack type has been the most dominant unit type among the best-practice example adult ICUs during the last two decades accounting for $73.33 \%$ of all the units.

The appeal of the racetrack type unit may be due to the perception that it provides more perimeter wall for more patient rooms with natural light and outside view; that it accommodates more compact and centralized support and service areas which is optimal for care and care-related functions; and that it helps reduce the physical distance from patient rooms to support and service areas. In contrast, corridors in a racetrack type layout wrap around and cut across a core of support and service areas (see Figure 3). Therefore, a racetrack type layout may require more corridors and may force staff to walk more despite the perception that it helps reduce the physical distance from patient rooms to support and service functions.

Some evidence supporting the above claims was found in the study of space allocation among different generic categories of functions - patient room area, support and service area, and circulation area - in the award-winning ICUs. The study excluded the ICU with a radial unit type layout since it had a large unidentified space in the center. The study of space allocation found that the racetrack type units had the highest mean of the total patient room area as percentage of unit gross area among all the unit types (Figure 5A) supporting the claim that the layout might provide most space for patient rooms. The study also found that the racetrack type units had the lowest mean of the total support and service areas as percentage of unit gross area among all the unit types (Figure 5B) supporting another claim that support 


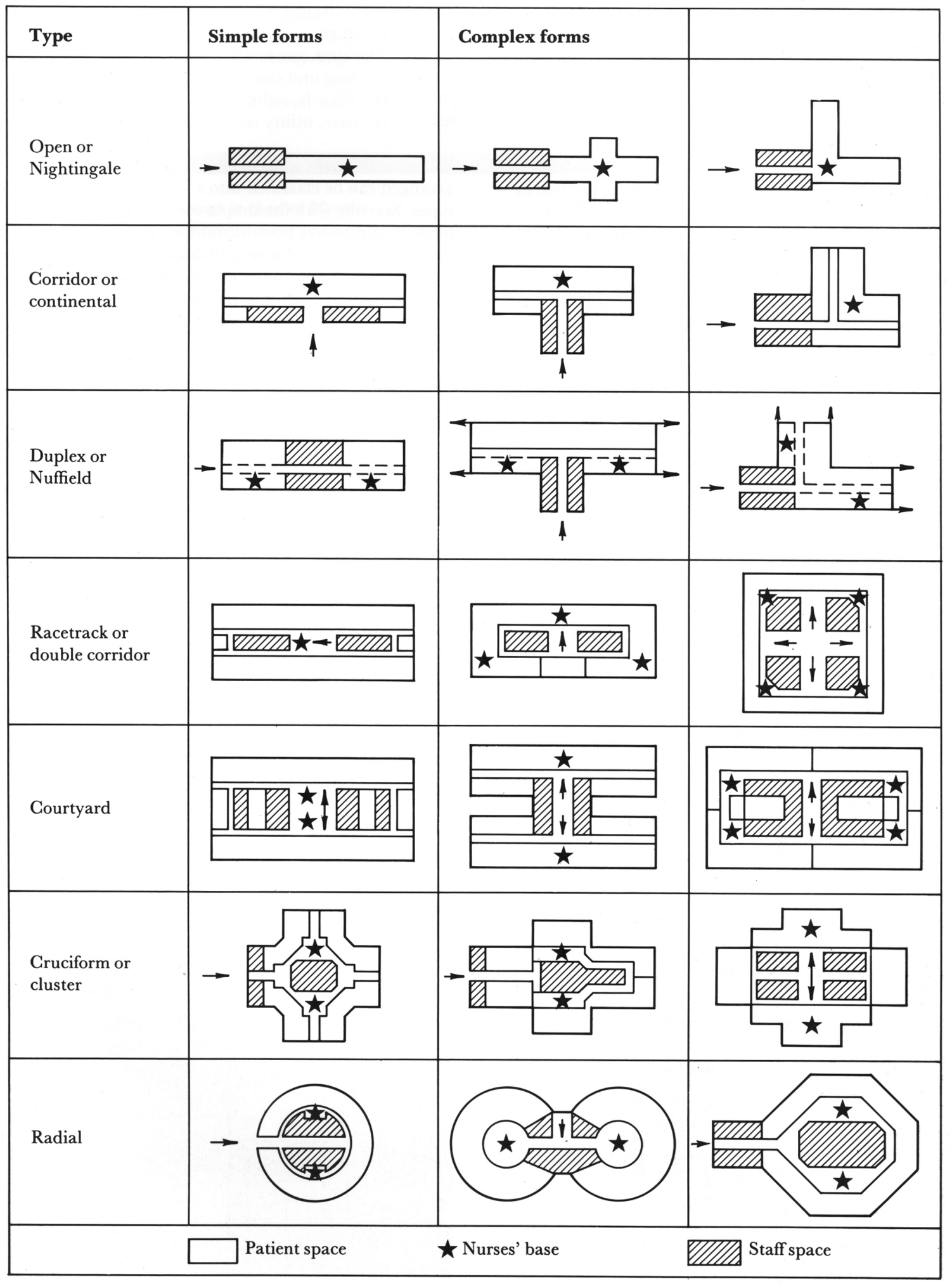

Figure 3: Different types of unit layout. [Source: 24. With permission from Elsevier.] 


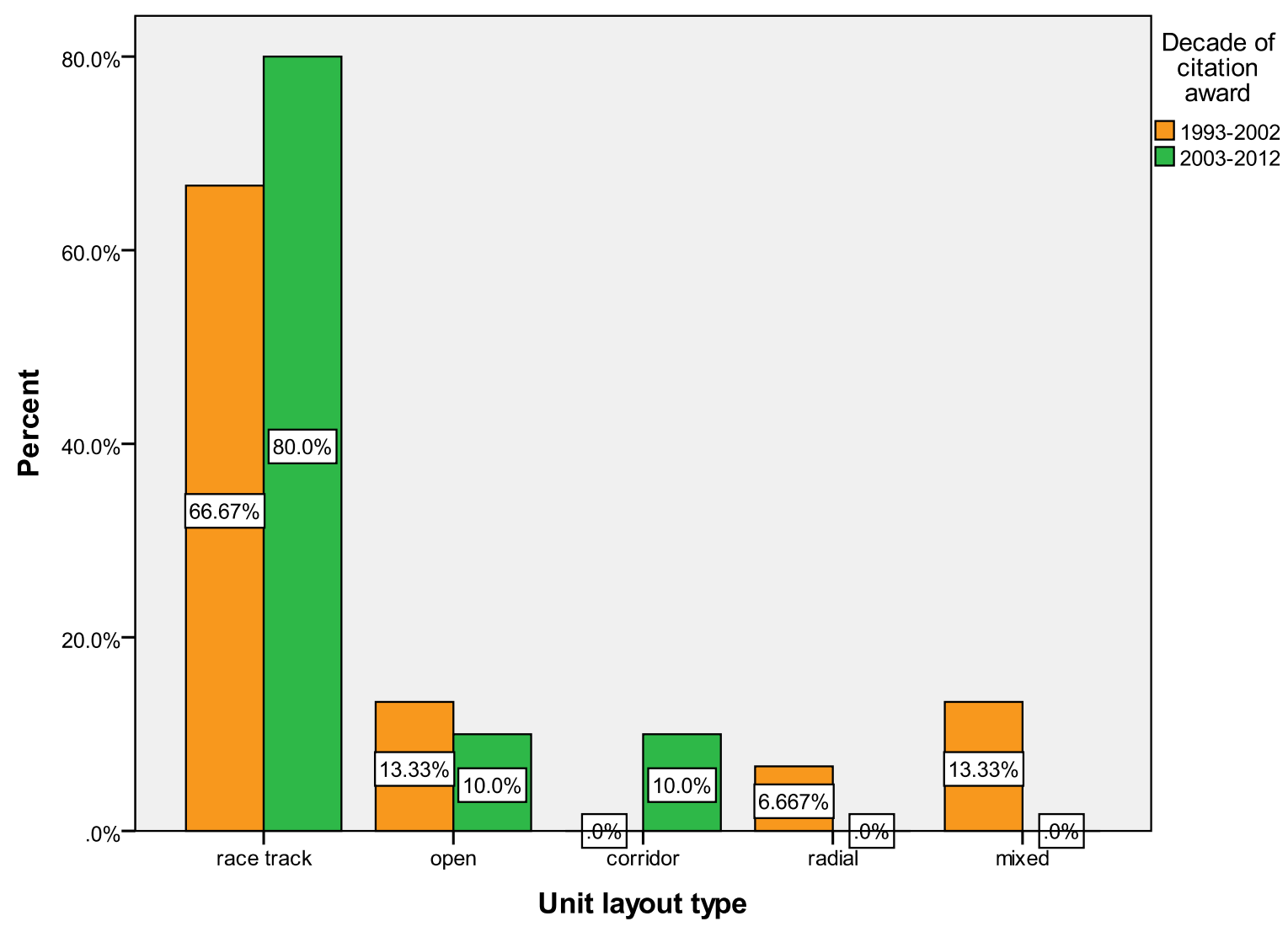

Figure 4: Different types of unit layout by decade. 
and service areas would be more compact in the layout. Additionally, the study found that the racetrack type units had the highest mean of the total circulation areas as percentage of unit gross area among all the unit types (Figure 5C) supporting yet another earlier claim that a racetrack type layout might require more circulation spaces. Therefore, more studies are required to understand how these contradictory aspects of a unit layout type affect patient care and other outcomes.

\section{Unit size}

The size of an ICU must be appropriate for constant visibility between ICU patients and care providers. It must also be appropriate for care providers to become fully aware of all the people, not just the patients, and activities on the floor. Additionally, the size must also be appropriate for less walking and noise. Smaller units that fulfill these needs better, however, may not permit efficient staffing. Smaller units may not also justify having a procedure room, a satellite lab, a radiologic unit, a satellite pharmacy, an appropriately sized family waiting space or a staff lounge; thus, affecting safety, efficiency, family integration, and staff comfort and satisfaction.

Literature suggests maximum eight to 12 beds per unit for better observation [13-15]. In general, larger ICUs with more beds have more infections [for example, refer to 28-30]. Therefore, when units have more than 12 beds they can be divided into clusters or pods of six to eight to permit efficiency and economy. Staffing models should also be considered in determining the size and clustering of a unit. For example, for a 2:1 staffing model (2 patients for 1 nurse) it is better to have even numbers of beds in an ICU or in the clusters of an ICU. For this reason, units with 12, 16, and 20 beds may work better. A 24bed unit can have two 12-bed pods, but these large pods may not be optimal for efficiency and economy. A 24-units can also have an asymmetrical layout with three pods of 8-bed, where it may be difficult to find optimal locations for support and service functions in relation to patient rooms.

This study shows that the average number of patient beds was 20.67for the 1993-2002 ICUs, whereas it was 26.6 for the 2003-2012 ICUs. In other words, the 2003-2012 adult ICUs were bigger by more than six beds. The average for all the units was 23.63, which is also a much higher number than the numbers recommended by the SCCM Guidelines [3, 12] and by ICU experts [13-15]. Neither an operationalfunctional perspective nor a socio-ecological perspective can fully justify very large ICUs, even when these units are broken down into smaller pods [1]. Therefore, studies are needed to understand why the award-winning ICUs have such a high number of patient beds. 

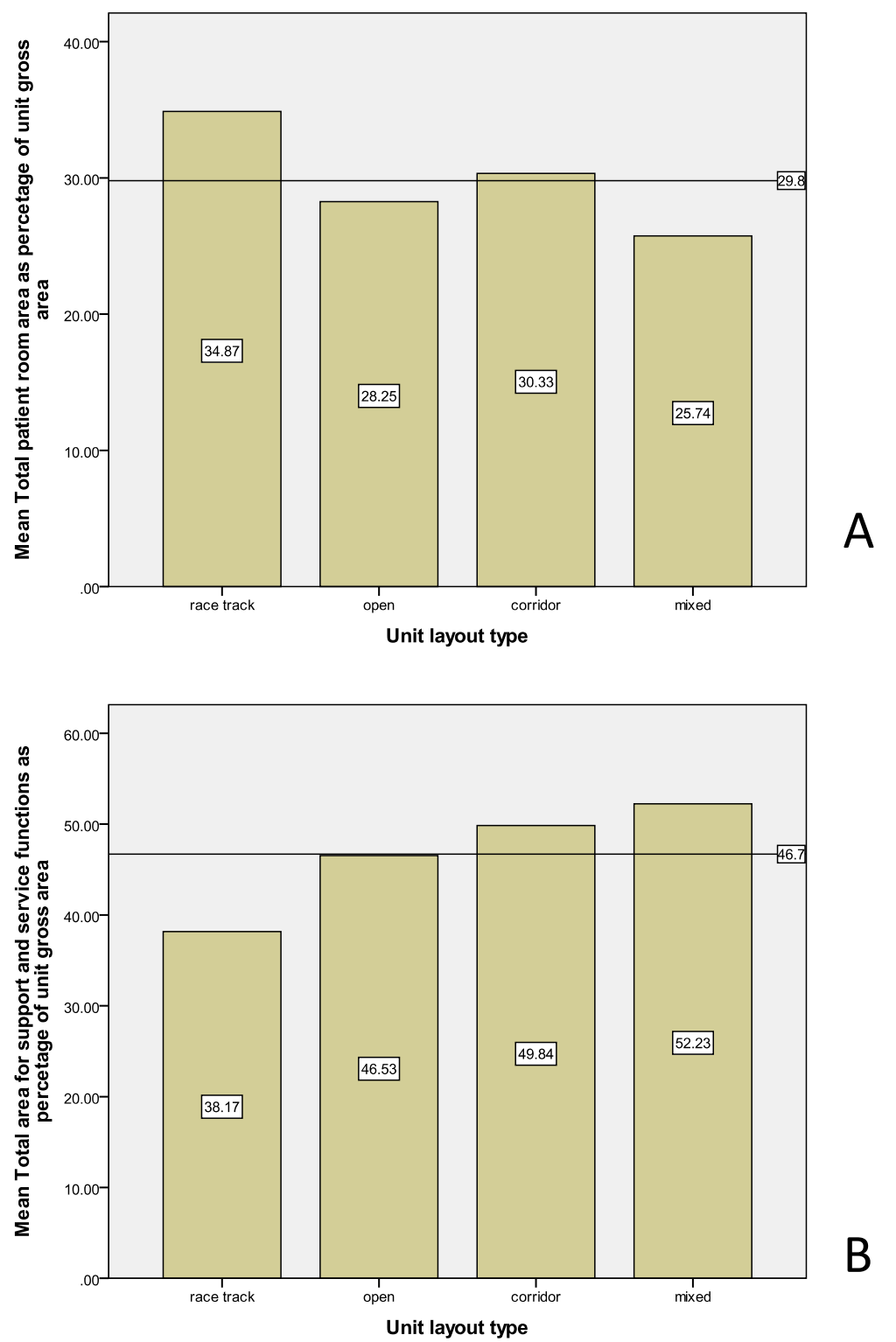

B

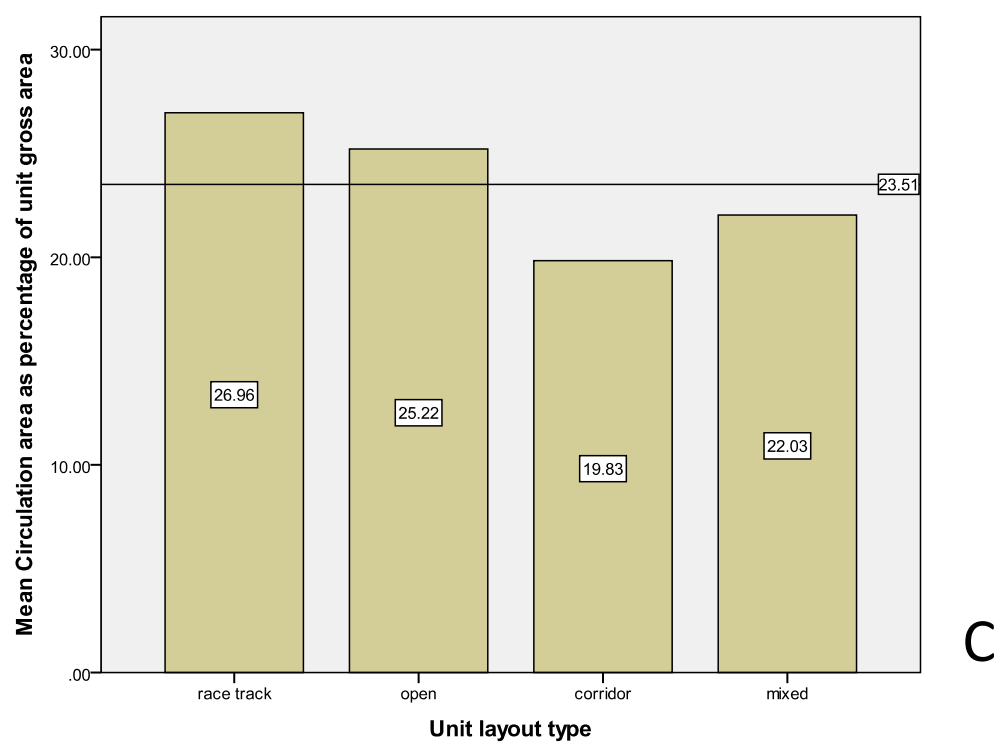

Figure 5: Space allocation per unit layout type. (A) Mean total patient room area as percentage of unit gross area. (B) Mean total area for support and service functions as percentage of unit gross.

(C) Mean total circulation area as percentage of unit gross area. area. 
To understand the relationship between unit size defined in terms of the number of beds in a unit and unit size defined in terms of square footage, a correlational analysis between the number of beds and unit gross area was performed. The analysis found a significant positive correlation between the number of beds in the unit and the gross area of the unit $(r=0.639 ; \mathrm{p}<.01)$ indicating that as the number of beds increased so did the size of the units. Though a simple regression model showed that the predictive power $\left(r^{2}\right)$ of the number of beds in the unit over the gross area had decreased from 0.49 in the previous study [1] to 0.4 in the present study, the pattern seemed to have persevered over the last two decades between 1993 and 2012. The finding that the gross area of the unit might be a function of the number of beds in the unit was also supported by a significant positive correlation between the gross area per bed and the gross area of the units $(\mathrm{r}=0.787 ; \mathrm{p}<.01)$. This finding indicates that as the gross area of the unit increased so did the gross area per bed in the unit or vice versa. Therefore, the present study indicates that the ICUs with more beds generally had larger gross area.

\section{PATIENT ROOM DESIGN ISSUES}

\section{Patient room size}

The most important component of the patient care zone in ICUs is the patient room. In determining its size, the needs of the patient, care providers, and families must be considered. After leaving adequate space for care providers and families, all patient rooms should comfortably fit the patient bed and several other devices, equipment, and procedures involved in critical care.

According to the FGI Guidelines, separate rooms or cubicles for single patient shall have a minimum clear floor area of 150 square feet [2:100], which is the area available for functional use exclusive of the space occupied by the patient, toilet, closets, lockers, wardrobes, alcoves, vestibules, anteroom when available, and other auxiliary work areas in the room. Sometimes, floor space below sinks, counter, cabinets, modular units, or other floor hang equipment can contribute toward clear floor area [2: xxix]. However, the FGI Guidelines also indicates that the size of the patient room should be determined by the intended functional use. That is because if designed to the absolute minimum clear floor area, the patient room may be overwhelmed due to several devices, equipment, and procedures involved in care [2:100].

One major device that occupies the patient room, but that does not occupy the clear floor area, is the patient bed. According to the FGI Guidelines, all patient beds shall have a minimum clear dimension of 1 foot from the headwall, 5 feet from the foot wall, 5 feet on the transfer side, and 4 feet on the non-transfer side [2:100]. Therefore, the required 150-square feet clear space leaves very little space for devices, 
equipment and procedures in the patient room if the patient bed clearance requirements are considered. The required clear space would leave even less space for all other things if the 2012 SCCM Guidelines' patient bed clearance requirements were considered: "Single-patient rooms should have an optimal clearance of not less than 4 feet at the head and foot of the bed and not less than 6 feet on each side of the standard critical care bed.” [3:1588]

This study shows that the average patient room size was 250.4 square feet for the 1993-2002 ICUs. This square footage for patient rooms was recommended by the earlier 1995 SCCM Guidelines [12]. In contrast, the average size was 266.5 square feet for the 2003-2012 ICUs; that is, 16.1 square feet larger than the average size of the earlier decade. As a result, for the whole sample the average patient room size increased to 258.45square feet. These findings indicate that the award-winning ICUs of both the decades probably included much larger clear floor space in the patient room than that required by the FGI Guidelines, thus suggesting additional space need for an optimal care environment. The findings also indicate that the demand for space in the patient room might have been on the rise in the more recent years due to increasing family integration with patient care and increasing demand for point-of-testing services and other procedures in the patient room.

To understand how the patient room size was associated with unit gross area in this sample of ICUs, correlational analyses were performed between the patient room area and unit gross area and between the patient room area and the gross area per bed. The analyses found a significant negative correlation between the patient room area and the gross area of unit $(r=-0.517 ; \mathrm{p}<.01)$; and between the patient room area and the gross area per bed $(r=-0.674 ; \mathrm{p}<.01)$. These findings indicate that as the gross area of the unit and the gross area per bed increased the patient room area decreased in this sample of ICUs. This is interesting in light of the previous findings that showed as the number of beds increased so did the size of the units. In simple words, even though unit size might have increased due to an increase in the bed number, paradoxically bigger units with more beds had smaller areas for patient rooms in the awardwinning ICUs.

\section{Private patient rooms}

According to the literature, single private patient rooms are better than multi-bed rooms in terms of patient safety because they increase isolation capacity and facilitate filtration, ventilation, and airflow control. Single patient rooms also provide more privacy, and improve interaction and sleep quality [for example, refer to 8-9, 31-35]. 
Despite the importance of private patient rooms, the FGI Guidelines' requirements for private patient room are vague. It states that, consistent with the delivery care model (for example, patient-focused care or family-centered care), appropriate level of patient privacy and confidentiality shall be addressed in the design of a healthcare unit or facility [2:15]. When private rooms and cubicles are provided, view panels to the corridor with a means to ensure visual privacy shall be provided [2:100].

Yet, this study shows that in the 1993-2002 ICUs $95.33 \%$ of the patient rooms were private rooms. In contrast, in the 2003-2012 ICUs100\% of the patient rooms were private rooms. For the whole sample $97.67 \%$ of the patient rooms were private rooms. These findings indicate the private patient room has remained an important feature among the award-winning ICUs of the last two decades.

\section{Isolation rooms}

Isolation rooms are important for immunosuppressed patients and for patients with infectious diseases. For example, in a review of the literature on the isolation of cystic fibrosis patients, it was found that isolation halted cross-infection of Pseudomonas aeruginosa among these patients [36]. Isolation rooms also substantially reduce the incidence of infection and mortality among burn patients and other vulnerable or immunosuppressed patient groups [37-38].

According to the FGI Guidelines, the isolation room requirements shall be determined based in the needs of specific community and patient populations served by an individual healthcare organization [2:48-49]. The 2012 SCCM Guidelines' recommendations are no different from the FGI Guidelines [3]. In simple words, according to the requirements of the FGI Guidelines and the SCCM Guidelines isolation rooms are optional for ICUs.

Yet, very large percentages of best-practice example ICUs of the last two decades included isolation rooms. The percentages of ICUs with isolation rooms were $58.82 \%$ and $55.56 \%$ for the first and the second decade, respectively. Despite the fact that fewer ICUs had isolation rooms in the second decade, the number of isolation rooms per ICU increased notably in this decade. The mean number of isolation rooms for the 1993-2002 ICUs was 1.87. In contrast, the mean for the 2003-2012 ICUs was 2.46. When the ICUs with isolation rooms were considered separately, the mean of isolation rooms for the 2003-2012 ICUs was even higher (2.8 for the 1993-2002 ICUs vs. 3.86 for the 2003-2012 ICUs). These findings indicate that, though optional, in many communities and patient populations immunocompromised diseases are real enough to determine the need for isolation beds in ICUs. 


\section{The Configuration of life support and medical utilities and patient bed location}

Life support and medical utilities in a patient room include medical gasses, vacuum, data, and electrical outlets. The fixed headwall systems, the fixed, rotating or suspended column systems (also known as power columns), the rotating booms mounted on ceiling or wall, the sliding systems mounted on beams, or some combinations of these systems are among the many ways life support and medical utilities can be brought to the patient bed. Each of these systems provides different ways to access utilities. As a result, they provide different amount of flexibility in laying out the patient bed within the patient room impacting care.

In general, booms provide the highest degree of accessibility and flexibility in the patient room, followed by power columns, and then by headwalls. However, booms are also the most expensive and architecturally demanding systems, followed by power columns, and then by headwalls [for further discussion on these systems, refer to $1,3,17,39]$. Since the life support and medical utility systems are important both for cost and care, the 2012 SCCM Guidelines states, "The design team should consider the patient type, functional plan, staff preferences, technology trends, and potential future needs” when selecting these systems [3:1588].

This study shows that, of the 1993-2002 ICUs, 13.33\% used head walls, $60 \%$ used power columns, and $26.67 \%$ used the ceiling or the wall mounted arms. In contrast, of the 2003-2012 ICUs, 20\% used head walls, $40 \%$ used power columns, and 40\% used the ceiling or the wall mounted arms (Figure 6). Therefore, there was a decrease in power columns and an increase in booms in the second decade. However, despite the differences, the location of patient beds in these units did not change noticeably from the ICUs of the first to those of the second decade. That is because both power columns and booms allow for free-standing beds. As a result, of the 1993-2002 ICUs, 86.67\% units had free standing beds and 13.33\% had beds against the head wall. In contrast, of the 2003-2012 ICUs 80\% units had free standing beds and $20 \%$ had beds against the head wall. Power columns and booms may not have significant effects on the location of the bed, but they have significant cost differences. Therefore, future studies should look at the other benefits of booms over columns that helped the award-winning ICUs of the second decade choose booms over power columns. 


\section{Patient room toilets}

The primary purpose of toilets in ICU patient rooms is to provide a safe and enclosed area where blood and body fluids can be easily disposed. Thus, these toilets may often include clinical sinks, which is a flushing-rim sink or "hopper” for bedpan washing and drainage of suction canisters [2:101].

This study observes different types of toilet in the patient room of the award-winning ICUs. They were shared or private full bathrooms, shared or private half bathrooms, shared or private toilets in enclosed spaces, open toilets with privacy curtain, and foldout toilet under counter. Since relatively few ICU patients are expected to use conventional toilets, a private or shared full bathroom is not needed for the patient room. Some award-winning ICUs include a full private bathroom in the patient room anyway as a family amenity to improve family integration. Though the effects of these full bathrooms on safety are not known, it can be assumed that these bathrooms may become a breeding ground for microbes without appropriate cleaning regimens. In contrast, shared toilets or bathrooms can contribute to cross infection such as the spread of $C$. difficile [40]. Many ICUs use foldout toilets or commodes to increase the clear floor area in the patient room. These toilets can create infection control concerns due to aerosol sprays [41], and they are not often rated for bariatric patients. A better solution for ICUs may be a floor mounted open toilet with privacy curtain. This type of toilet provides greater bearing capacity for bariatric patients [42], and requires less cleaning efforts. However, for patient rooms with floor-mounted open toilets, direct access to an enclosed clinical sink may be required within or between rooms to dump bedpans and to prevent cross-contamination by aerosol spray.

According to the findings of the study, there were notable differences between the 1993-2002 and the 2003-2012 ICUs (Figure 7), particularly with regards to toilets with privacy curtain. Whereas in the first decade only $6.67 \%$ of the patient rooms had toilet with privacy curtain, in the second decade $40 \%$ of the patient rooms had this type of toilet. Another difference was that with $26.67 \%$ shared bathroom was the most common toilet type in the first decade; in contrast, only $10 \%$ of the patient rooms had shared bathroom in the second decade. Yet another difference was that in the first decade at least $13.33 \%$ of the patient rooms had half bath (private toilet with no shower), but in the second decade no patient room had half bath. Finally, compared with the first decade, fewer rooms had foldout toilet under counter in the second decade (20\% vs. $10 \%$ ). In both the first and the second decades, however, $20 \%$ of the patient rooms had full private bathrooms. In light of the above discussion, most of these findings would indicate improvements regarding toilets in patient rooms. Yet, more studies are needed to understand the effects of different types of toilets on patient and staff safety in ICUs. 


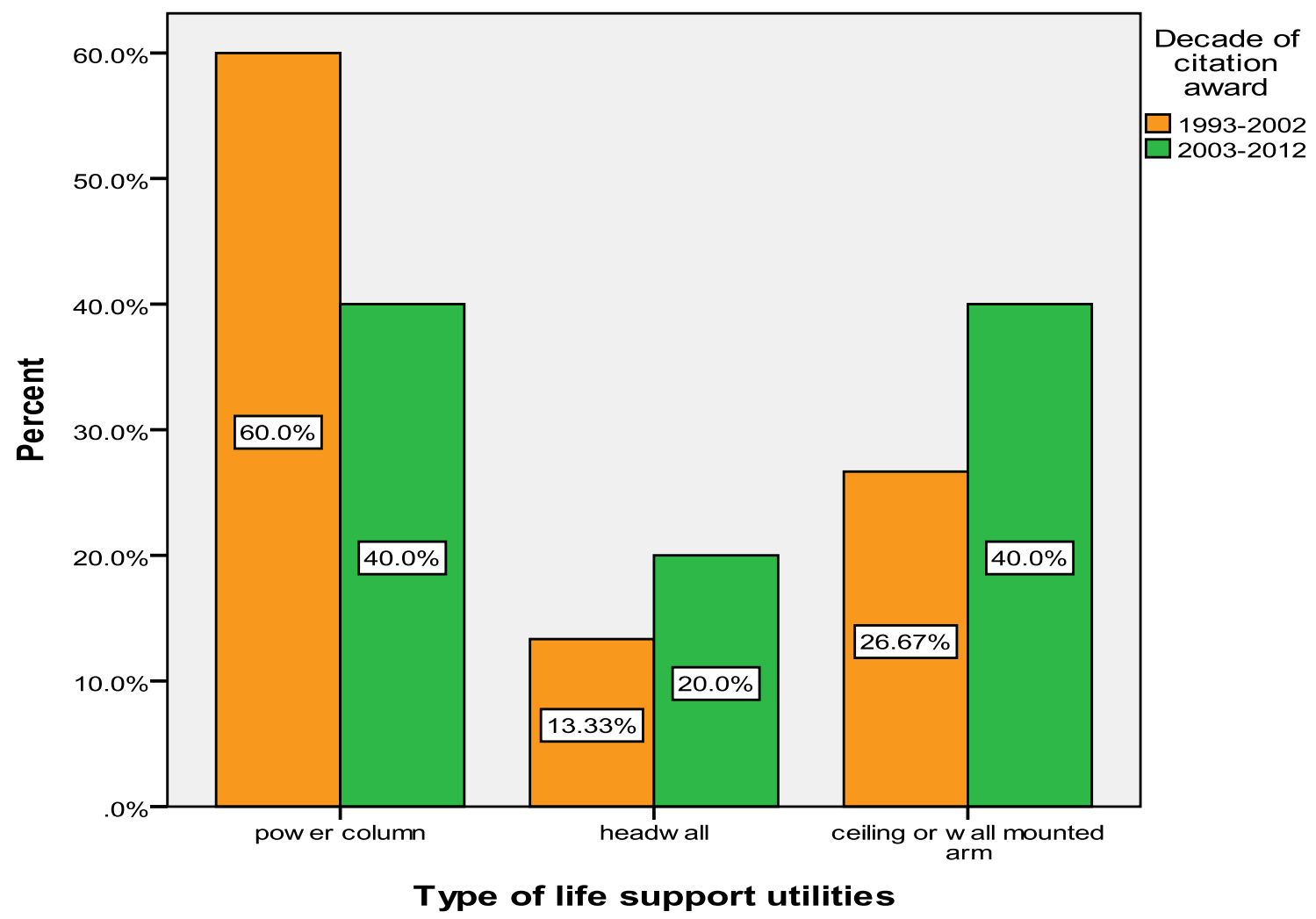

Figure 6: Different types of configuration for life support systems and medical utilities by decade.

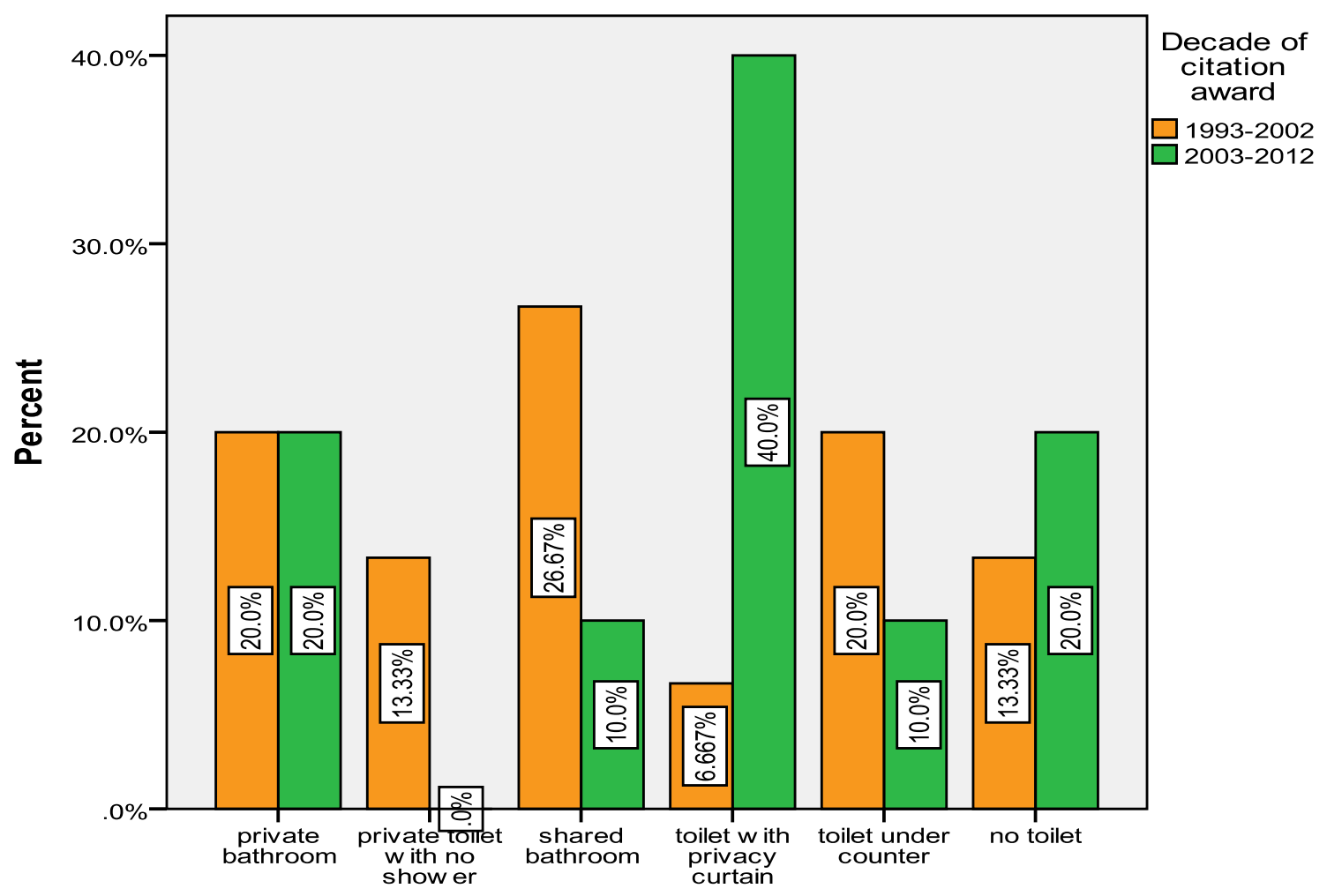

Toilet type in patient room

Figure 7: Different types of toilets in patient rooms by decade. 


\section{Natural light and outside view}

Natural light and outside views are important for patients. Among other things, they help improve mood, relieve anxiety and stress; reduce the patient's medication intake; reduce the patient's length of stay; and improve the patient's orientation [for example, refer to 43-49]. Therefore, the FGI Guidelines advises that natural light and views of nature should be considered whenever possible in the design of the physical environment of all healthcare facilities. To the highest extent possible, the source of such natural light should also provide opportunities for exterior views [2]. The SCCM Guidelines also advises that each patient care space should provide visual access to the outdoors, other than skylights, with not less than one window of appropriate size per patient bed area. In cases where a patient's bed must face the interior of the unit to permit close observation by staff, an adjustable mirror mounted on the wall or ceiling may provide the patient a view of the outdoors [3:1589].

Likewise, this study shows that natural light in the patient room was important for the award-wining ICUs of both the decades. In the 1992-2003 ICUs 88.62\% of the patient rooms had access to natural light; and in the 2003-2012 ICUs $87.61 \%$ had access to natural light. In the first decade, out of the patients room with access to natural light $66.67 \%$ of the ICUs had direct natural light, $33.33 \%$ had both direct and borrowed natural light; and none had only borrowed light. In the second decade, out of the patients room with access to natural light $70 \%$ of the ICUs had direct natural light, $20 \%$ had both direct and borrowed natural light; and 10\% had only borrowed light.

Outside views from the patient room was also important for the award-wining ICUs of both the decades. In the 1992-2003 ICUs $84.67 \%$ of the patient rooms had outside views; and in the 2003-2012 ICUs 76.30\% had outside views. Since the ICUs of the second decade had more patient room with borrowed natural light they also had fewer patient rooms with outside view.

The higher percentages of patient rooms with access to natural light than with outside views in the ICUs of both the decades indicate that more efforts were made to bring in natural light to patient rooms, and that some patient rooms were given access to natural light but not to outside views. Nevertheless, the findings of the study suggest that access to natural light and/or outside view from the patient room remains a hallmark of the award-winning ICUs. 


\section{Patient room doors}

Patient room doors are important in ICUs. Opaque doors may restrict visibility between patients and staff when kept closed for privacy and noise. A conventional double-swing glass door or sliding door that works well for the patient rooms in other inpatient units may be inconvenient for ICUs, because these doors can restrict easy movement of an ICU patient who is often hooked to one or more life supporting equipment. The swing of these doors can also make additional space unusable. Sometimes, many lifesaving procedures must occur in ICU patient rooms, for which additional people and equipment may be required. A door with breakaway capacity may be useful for these events. Therefore, the 2012 SCCM Guidelines recommends sliding glass door with breakaway capacity for patient rooms, because, these doors “may provide beneficial additional width as well as increased visibility to the patient.” [3:1589]

In line with the recommendations, the study finds that the full-length sliding glass breakaway door was the most frequently used door type in the best-practice example ICUs of both the first and the second decades (53.33\% and 50\%, respectively). The full-length sliding glass door was the second most frequently used door, and the use of this type of door increased slightly in the second decade (20\% in the first decade vs. $30 \%$ in the second decade). In contrast, the use of the double swing doors decreased slightly in the second decade (26.67\% in the first decade vs. $20 \%$ in the second decade). These differences indicate some improvement regarding patient room doors in the best-example ICUs of the 2003-2012 decade.

\section{Hand-washing sinks}

Evidence suggests that the number, location, and type of hand-washing stations and hand sanitations dispensers are important for hand-washing compliance, which helps reduce cross-infection and improves safety [50-55]. Therefore, the FGI Guidelines recommends that the infection control risk assessment (ICRA) considerations shall include the number, location, and type of hand-washing stations, and hand sanitations dispensers [2:18]. The stations shall be convenient to nurse stations and patient bed areas. There shall be at least one hand-washing station in each patient room. They shall be located near the entrance to the patient room [2:101]. The SCCM Guidelines also makes similar recommendations [3].

Though the location of hand-washing sinks in relation to the patient room showed some differences between the 1993-2002 ICUs and the 2003-2012 ICUs, most of these ICUs adhered to the Guidelines. Hand-washing sinks inside the patient room was the most preferred option in both the decades, but the percentage of cases was higher in the second decade (73.33\% in the first decade vs. $90 \%$ in the second 
decade). One or two ICUs still did not have any hand-washing sinks either inside or outside the patient room in both the decades.

Hand-washing sinks were also at somewhat similar locations inside and/or outside the patient rooms of the ICUs of the first and the second decades. Some of these locations are shown in Figure 8 [reproduced in part from 1]. The near end of the footwall of the patient room was still the most preferred location in both the decades (46.67\% in the first decade vs. $50 \%$ in the second decade). The ICUs of the first decade also had $13.33 \%$ of the patient rooms with hand-washing sinks at the entry of the patient room; $13.33 \%$ at multiple locations within the patient room; $13.33 \%$ at the far end of the foot wall of the patient room; and $6.67 \%$ at the middle of the footwall of the patient room. In contrast, the ICUs of the second decade had $20 \%$ at the entry of the patient room; $10 \%$ at the far end of the foot wall of the patient room; $10 \%$ at the middle of the footwall of the patient room; and none at multiple locations within patient room. In simple words, many did not put the sinks near the entrance to the patient rooms as recommended by the Guidelines.

\section{DESIGN ISSUES INVOLVING SUPPORT \& SERVICE AREAS}

\section{Staff work area layout}

As noted earlier, staff work areas composed of centralized nurse station, substations, observation stations, and/or charting area are the basic component of the support functions in the unit. The other support functions of the unit, not included in this study, are administrative offices, conference spaces, on-call rooms, staff lounge, restrooms and lockers, and pharmacy, laboratory, and imaging when available.

Among the most important functions performed in staff work areas are monitoring of patients, multidisciplinary team work, and charting and order/data entry. Direct monitoring requiring visibility of patients from staff work areas is an important part of patient care in ICUs. Studies show that better visibility of patients from staff work areas improves clinical outcomes, patient satisfaction, and the quality of care [25-27, 56]. Recognizing the importance, the FGI Guidelines states that there shall be direct or remote visual observation between the staff work area or nurse station/s or charting stations and all patient beds in the ICU providing a view of the patient while in bed. If a central station is chosen, it should be located to allow for complete control of all patient beds in the unit. It should be designed to maximize efficiency in traffic patterns. Patients should be oriented so that they can see the nurse but cannot see the other patients. If central station is not chosen, the unit should be designed to provide constant visual contact between the nurse and the patient [2:101]. Though not discussed elaborately in this paper, 


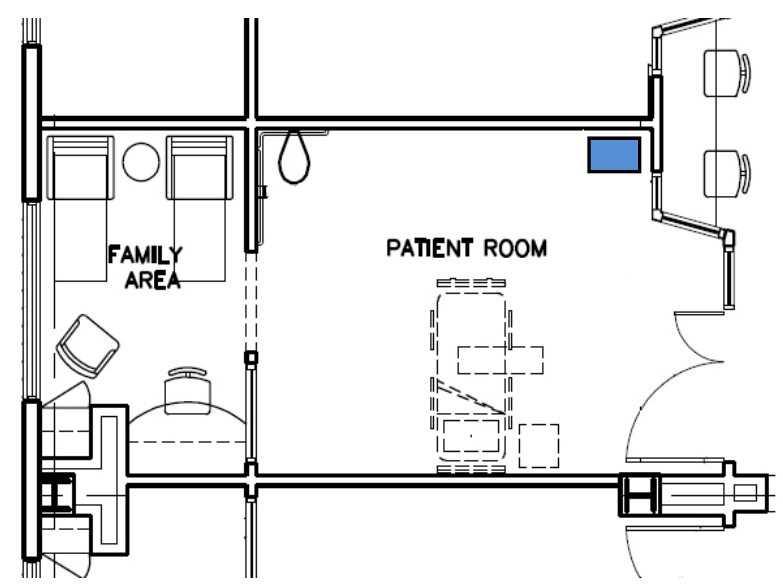

At the near-end of the footwall

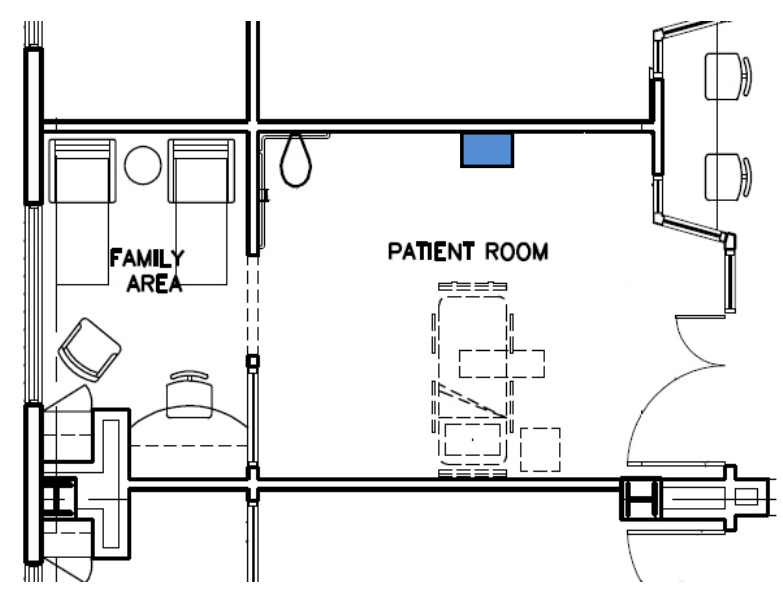

At the middle of the footwall

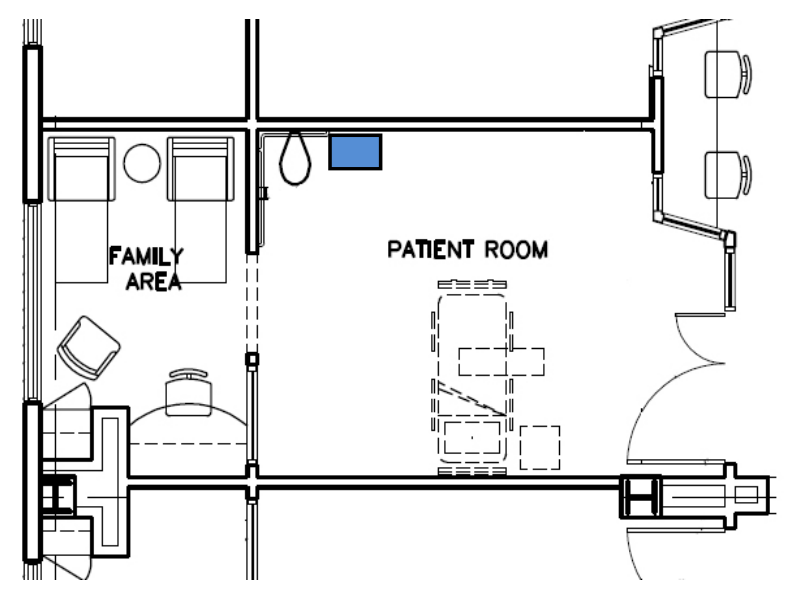

At the far-end of the footwall

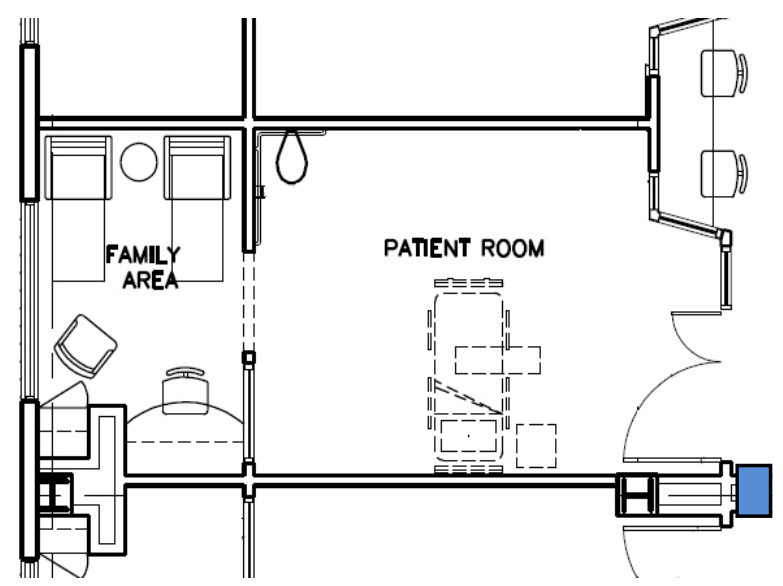

At the entry door

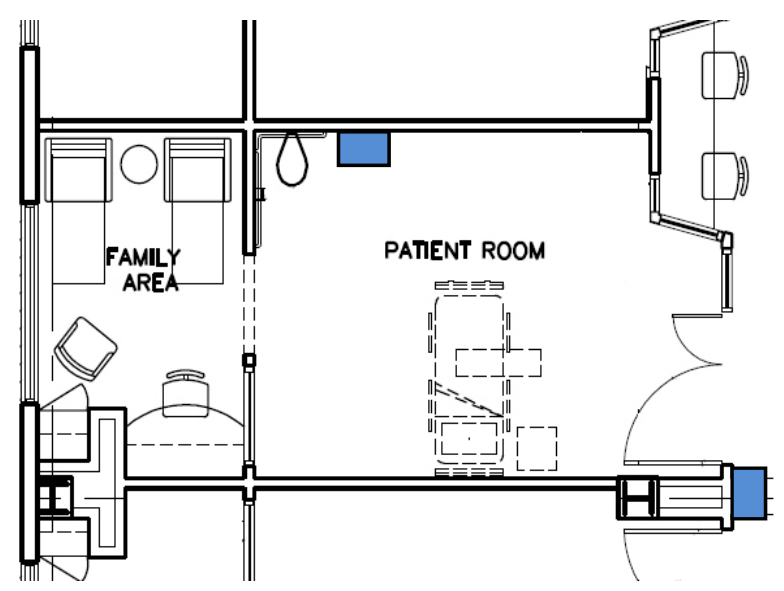

At multiple locations

Figure 8: Different locations of hand-washing sink inside and outside the patient room. [Reproduced in part from 11] 
nowadays remote monitoring has become another viable way to monitor ICU patients. Using web-based systems, it is now possible to send video-streams and physiologic and other live and pre-recorded data to specialists at remote locations in the hospital or elsewhere. These systems may offer enormous potential for maximizing scarce ICU resources, including intensivists, critical care nurses, and ICU beds [for a discussion on the topic, refer to 17].

Multidisciplinary medical teams are also an important part of critical care. They help improve quality of care in ICUs [57]. Therefore, staff work areas should include adequate spaces for team interaction with convenient access to computer, data, and telecommunication devices. Medical rounds are a common form of multidisciplinary interaction in ICUs. They provide opportunities to develop integrated care plans [5859]. Studies show that medical rounds can reduce cost and length of hospital stay and reduce mortality rates [60-61]. Since the formats of medical rounds can vary from one unit to another or from one staff physician to another, it is necessary that the staff work area layout be able to accommodate various rounding preferences and styles. Medical rounds in teaching hospitals often involve many people, and can soon become a source of noise and distraction in the unit. By defining where and how people interact during rounds, staff work area layout can play an important role in improving the critical care environment. In laying out the staff work area, it is also necessary to consider work surface area and technology requirements for documentation and review of patient records during medical rounds.

Charting and documentation are not unique to ICUs, but it is hard to create the right kind of environment for these functions in busy ICUs. It could potentially be done at the same work areas used for teamwork if these areas were designed to minimize interruption and distraction from noise and other environmental stimuli. A setting for charting and documentation would generally require dedicated computers, telephone, paper forms, pneumatic tube, fax machine, and digital technology conveniently located within the staff work area [3]. Given the importance of charting areas in ICUs, it will be discussed separately in the next section.

Finally, for the staff work area layout, in addition to the monitoring, interaction, and data entry needs, it is necessary to consider the physical and mental needs of those providing care and services in ICUs. When the staff is under stress, they become irritable, forget things, make mistakes, and suffer burnout. As a result, they quit. In light of serious shortage of critical care personnel in the USA, staff work areas in ICUs must be designed to help reduce staff stress, and improve performance and satisfaction.

According to this study, the award-winning ICUs tried many different options for laying out the staff work area with the aim of striking a balance among the monitoring, interaction, and other functional needs. Some had the more traditional centralized nurse station with monitoring, interaction, and 
documentation all at the same place. Some had two or more nurse substations, generally smaller than one large centralized station, in an effort to bring services closer to the patient room. Then, there were those that provided yet smaller one or more nurse substations with several observation stations in an effort to bring services even closer to the patient room. In these ICUs, the substations generally provided hubs for interaction and mentoring, and the observation stations supported monitoring, documentation and charting. Still, others provided only observation stations to further enhance patient monitoring, documentation, and charting. In some cases, these observation stations also supported medical rounding at the patient room. However, it is noteworthy that ICUs with observation stations only may lack appropriate space for informal interaction and mentoring, which are essential for promoting a supportive work environment and culture in ICUs. Some recent studies on the effects of centralized and decentralized nurse stations on nurses' behaviors may be helpful with regards to the staff work area layout [for example, refer to 62-63].

Rashid [1] identified seven possible types of configuration of staff work area using centralized nurse station, substations, and observation stations as the basic units of staff work area configuration (Figures 9 \& 10). Using these configurations, this study finds that in the first decade, $40 \%$ of the ICUs had staff primary work area composed of distributed observation stations only; $26.67 \%$ had nurse substations only; and the other 5 types accounted for $6.67 \%$ each. In the second decade, $60 \%$ of the ICUs had staff primary work area composed of substations and distributed observation stations; $20 \%$ had distributed observation stations only; and the other 2 types accounted for 10\% each (Figure 11). Therefore, the frequencies of use of different types of staff work area layout in the 1993-2002 ICUs were different from that in the 20032012 ICUs.

The preference for a layout composed of substations and distributed observation stations in 2003-2012 ICUs might have represented an effort to find a balance between the total decentralization that was more common in the 1993-2002 ICUs and the total centralization that might have been more common in the ICUs of the even earlier decades. Also notable is the fact that all seven different configurations of staff work area layouts were observed in the sample of the first decade. In contrast, there were only 4 different configurations in the sample of the second decade. Therefore, the best-practice example ICUs of the second decade indicated a relative consistency concerning the configuration of staff work area. 


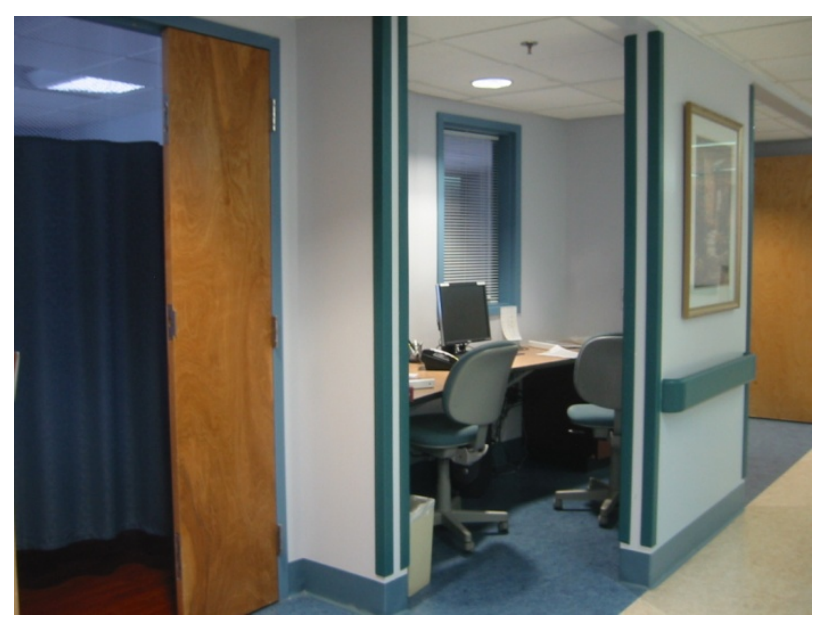

Observation Station

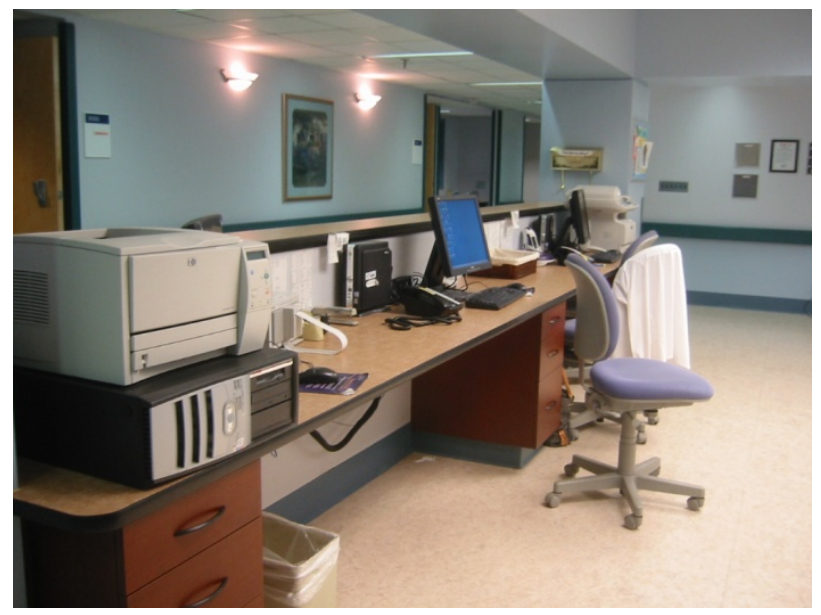

Substation

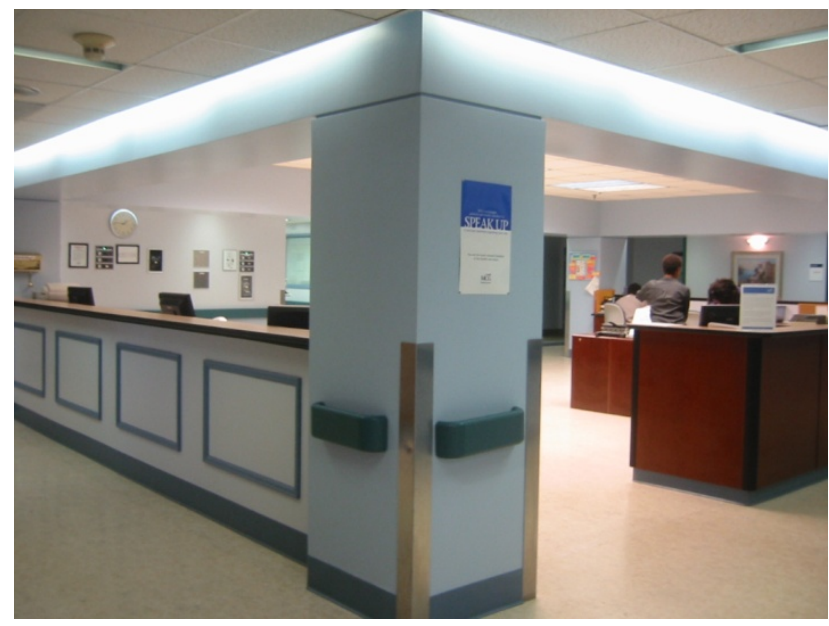

Central Station

Figure 9: Basic units of staff work area. [Source: 11] 


\section{Basic units of staff work area}

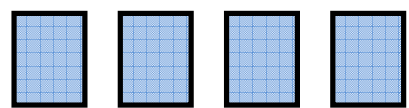

Observation Stations

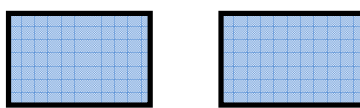

Nurse Substations

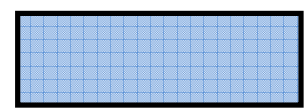

Centralized Nurse Station

\section{Possible Staff Area Configurations}

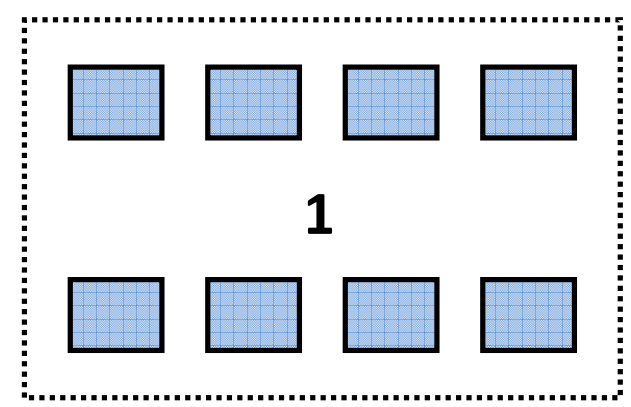

Observation stations only

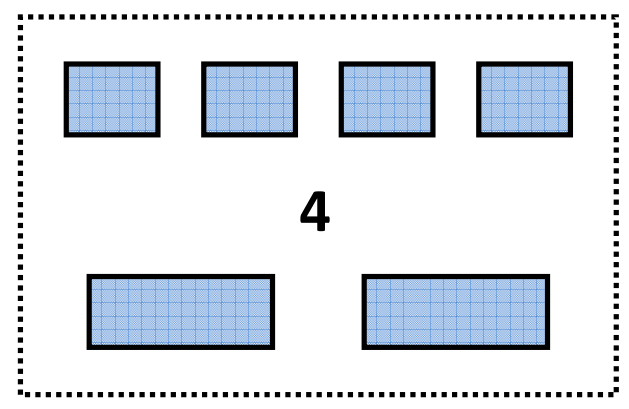

Observation stations and substations

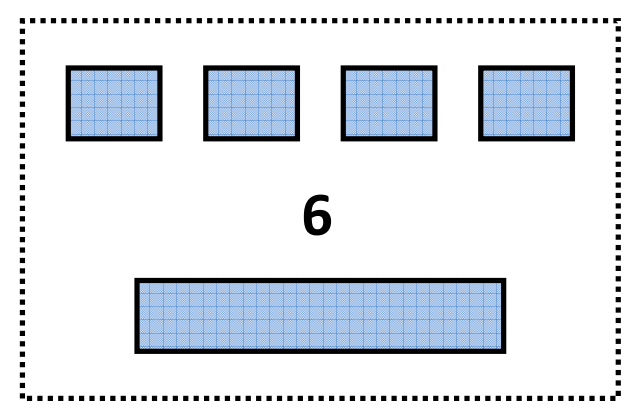

Centralized station and observation stations

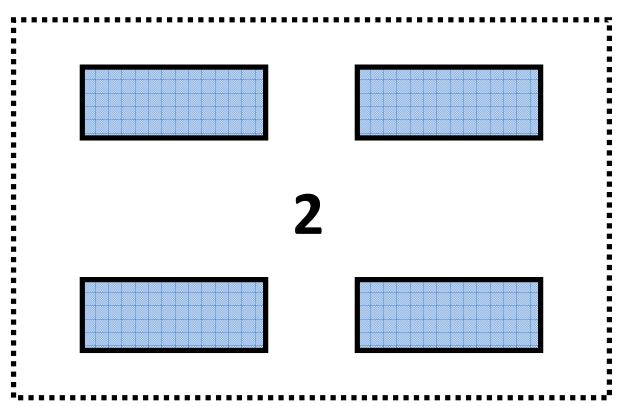

Substations only

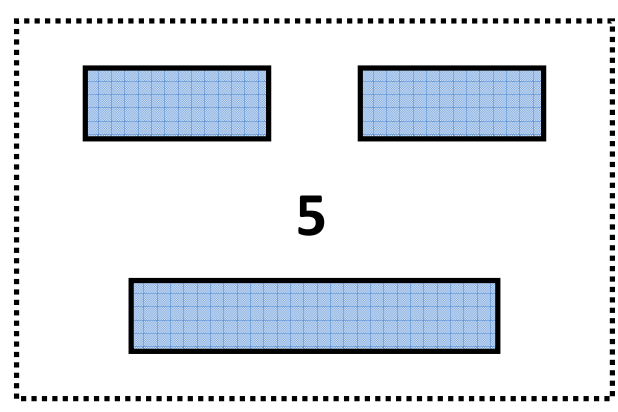

Centralized station and substations

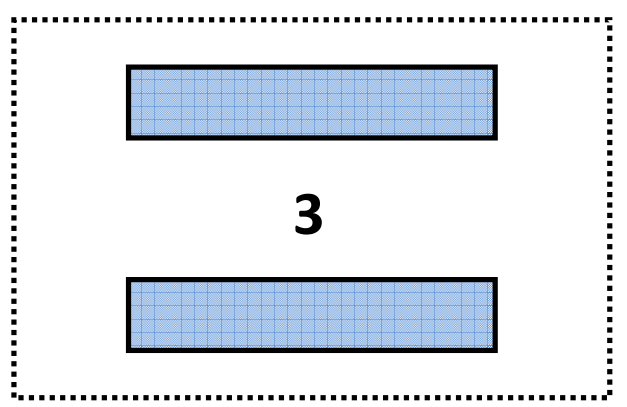

Centralized stations only

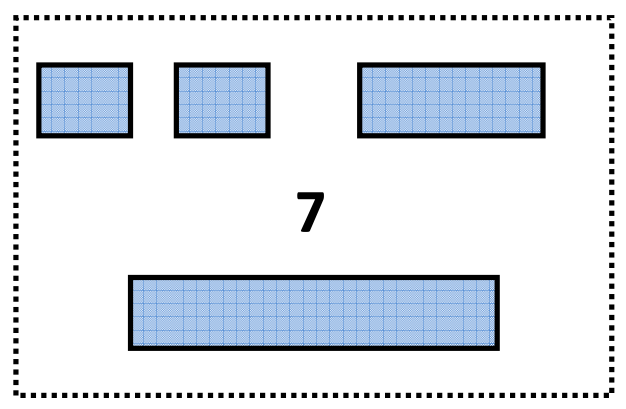

Centralized station, substation and observation stations

Figure 10: Basic units of staff work area and possible staff area configurations. [Source: 11] 


\section{Charting/documentation area location}

Charting/documentation areas, a component of staff work area, are areas where information specific to patients is recorded, stored and/or reviewed to facilitate ready access by authorized individuals. The requirements for documenting patient information by providers have become substantial and they continue to grow [3]. As noted earlier, these areas generally require dedicated computers, telephone, paper forms, pneumatic tube, fax machine, and digital technology.

According to the FGI Guidelines, the planning of charting/documentation area should consider the potential volume of clinical staff that could be present at any one time and translate that to adequate charting surfaces. These areas should be located within or adjacent to the patient bed space. While charting areas should be easily accessible, they should also be somewhat isolated to facilitate concentration. They should include countertop that would provide for a large flow sheet typical of ICUs and a computer. The FGI Guidelines requires one documentation space with seating for each patient bed [2].

This study finds similarities as well as differences between the 1993-2002 ICUs and the 2003-2012 ICUs regarding the location of charting area/s in relation to the patient room (Figure 12). The location immediately next to the patient room remained most popular in both the decades $(46.67 \%$ in the first decade vs. 50\% in the second decade). However, the number of ICUs with charting areas away from the patient room decreased from $26.67 \%$ in the $1993-2002$ ICUs to $10 \%$ in the $2003-2012$ ICUs. This is a positive development, since errors can occur when charting and documentation are done away from the patient room due to a time gap between collecting and recording the information, and since walking among nurses can increase when they need to move between the patient room and the nurse station for charting and documentation.

The study also finds, whereas none of the 1993-2002 ICUs had charting areas both inside and outside the patient room, 20\% of the 2003-2012 ICUs had them at both locations. This is also a positive development since having charting stations both inside and next to the patient room gives nurses more flexibility concerning where, when, and how they can record patient information.

\section{Service area layout}

As noted earlier, service areas in the ICU include designated spaces that house auxiliary functions. Examples of these spaces include clean utility room, soiled utility room, patient nourishment space, med 


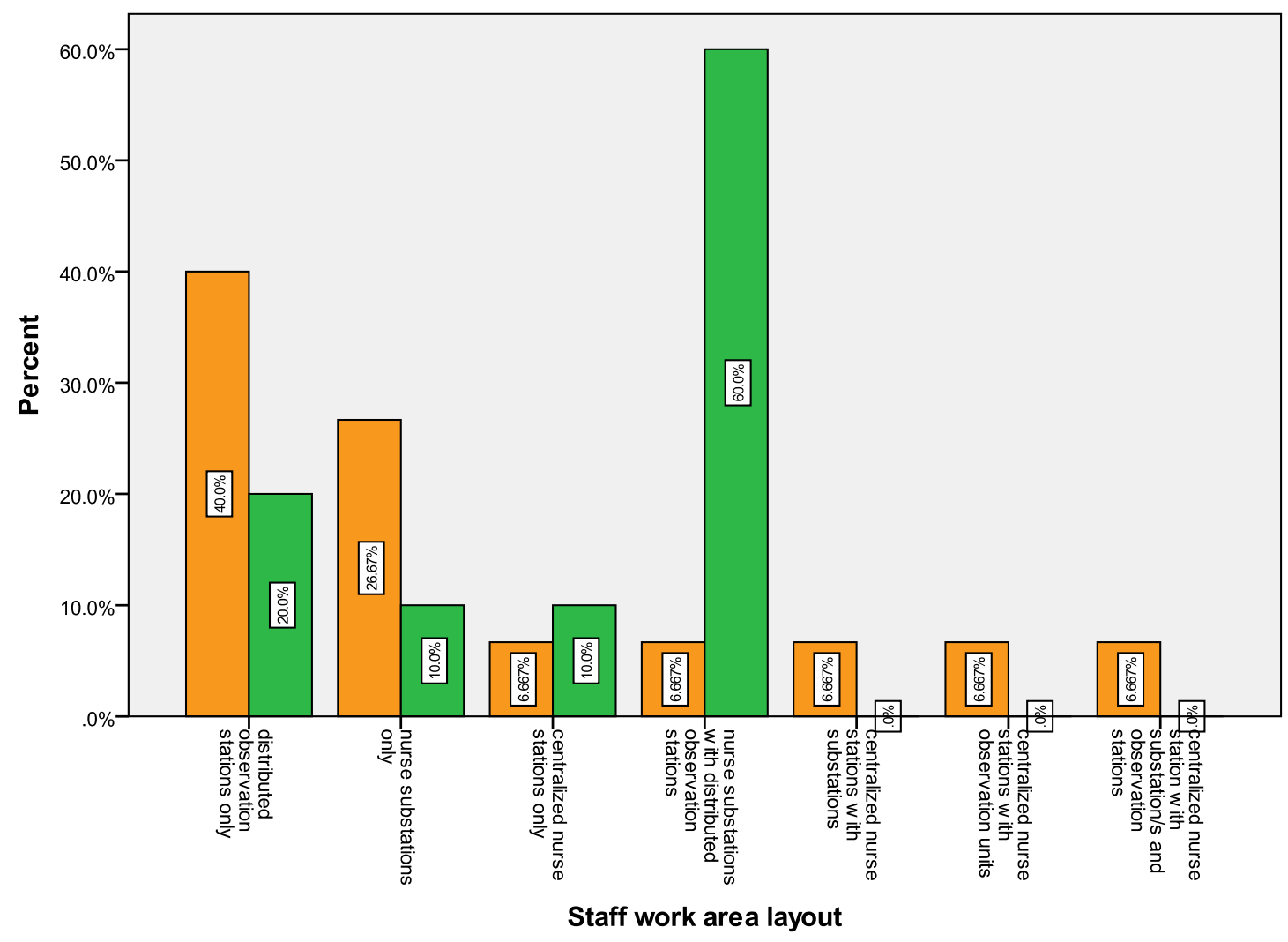

Decade of citation award

$\square$ 1993-2002

$\square 2003-2012$

Figure 11: Staff work area layouts by decade.

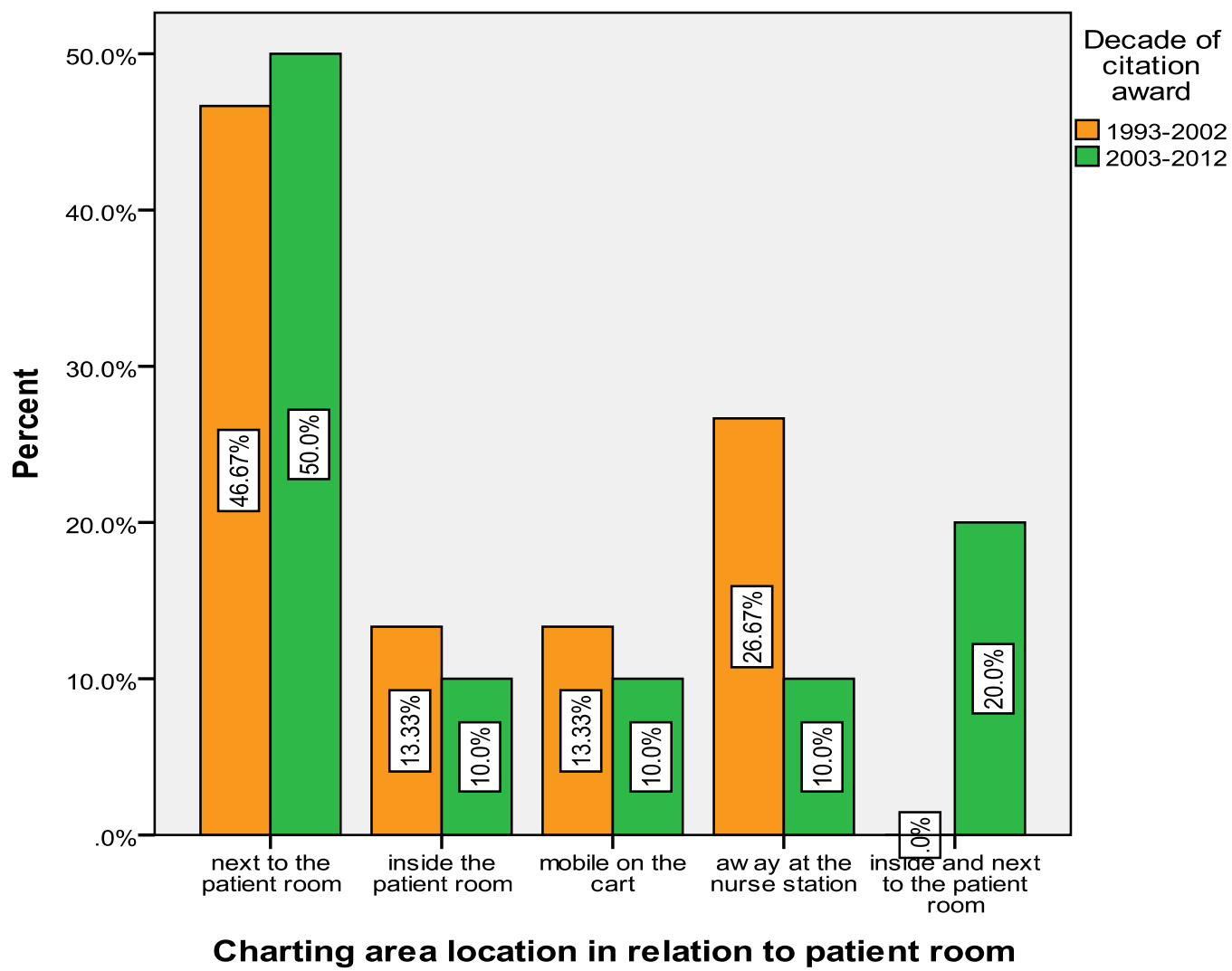

Figure 12: Charting area locations in relation to the patient room by decade. 
supply room, housekeeping, and any other storage spaces. Service areas must be sized appropriately depending on how supplies or services are delivered to the ICU. Some ICUs receive weekly supplies from central supply stores, therefore may need bigger storage areas. Others receive them daily from satellite locations, therefore may need smaller storage areas. Some spaces, like the soiled utility room, may be served more than one time per day or as needed. Inappropriately sized service areas may make stocking, servicing or staffing difficult.

Apart from size, the other two important aspects to be considered in laying out service areas are access and control. These areas must be conveniently located and easily accessible for nurses and support staff. Since tracking and controlling the flow of supplies in and out of supply rooms are essential for billing, centrally located service areas may improve flow and control but they may require longer trips from the patient room. In contrast, distributed service areas may improve access but they may worsen flow and control of supplies. Distributed service areas are also more difficult to stock when compared with centralized service areas. Yet, distributed service areas may become more common with more dispensing machines and wireless tags for supplies in ICUs.

According to this study, the layouts of the service areas in the 1993-2002 ICUs were remarkably different from that in the 2003-2012 ICUs (Figure 13). Sixty percent of the ICUs of the first decade used a centralized service area surrounded by nurse stations, but none of the second decade ICUs used this configuration of service area layout. This finding would indicate that access to service areas was controlled more in the first decade than they were in the second decade. This observation is also supported by the finding that $50 \%$ of the ICUs of the second decade had only distributed service areas, while none of the first decade ICUs used this option. In other words, as service areas became decentralized in the second decade to improve access and efficiency, the need to control the flow of supplies in and out of these areas by putting nurse stations around them also diminished. This diminishing control over service areas is further supported by the finding that even the centralized service areas in the ICUs of the second decade (40\%) did not have the nurse stations around them.

\section{FAMILY AREA DESIGN ISSUES}

\section{Common family waiting area locations in relation to the unit}

Increasingly, families are being integrated with care in many ICUs around the country. Still, there are many other ICUs where families are not welcome or families' access to patients is restricted because of the perception that families disrupt patient care, increase cross-infection, and contribute to noise and 


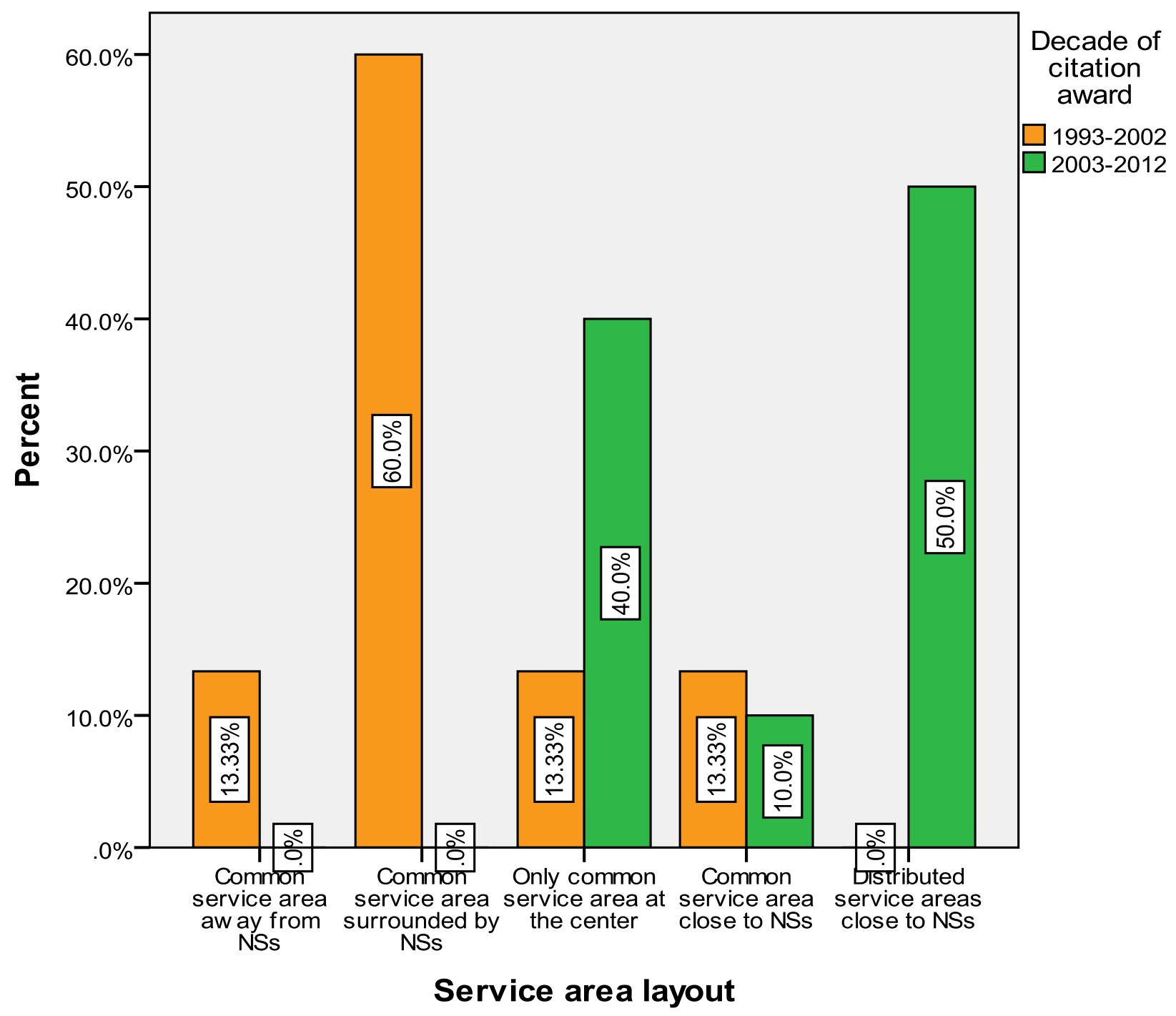

Figure 13: Service area layouts by decade. 
crowding in already crowded ICUs. Contrary to this perception, families often help improve patient outcomes and safety by providing emotional support, sharing the burden of care, and by supporting communication between patients and ICU staff [for a review of the literature, refer to 7]. However, patient families need physical and emotional support as well. They need access to information to help make appropriate decisions regarding care. They also need to stay physically and mentally healthy to share the burden of care.

Recognizing the importance of families in ICUs, the FGI Guidelines states, "The location and size of the family/visitor waiting space outside the patient room shall be provided as required by the functional program and shall provide a seating capacity of not less than 1.5 person per patient bed. This space shall include provisions for privacy, means to facilitate communication, and toilets that are readily accessible” [2:104]. In contrast, the 2102 SCCM Guidelines discusses several important features regarding family support zone including signage and wayfinding, family lounge, environmental considerations, meditation spaces, family communications, family nourishment, family sleep rooms, and family laundry [3]. Rashid [7] also provides a set of evidence-based design guidelines for family areas in ICUs.

This study focuses primarily on the location of common family waiting spaces in relation to the unit, since these locations often indicate the level of family integration in ICUs [1]. For example, ICUs with strong family integration may prefer to have common family waiting spaces placed closer to the unit or even within the units whenever possible to improve families' access to patients and ICU staff. In contrast, ICUs with weak family integration may prefer to have these spaces away from the unit, so that families have less access to patients and ICU staff. However, one must be careful not to read too much into the location of common family waiting spaces in relation to the unit. For example, it is easy to find family spaces outside many ICUs with strong family integration or inside many ICUs with weak family integration. That is because the location of these spaces may depend on many other factors, such as space availability and organizational culture, besides family integration.

This study finds that all ICUs of the sample had designated common family waiting space/s recognizing the importance of families in critical care, and the locations of these spaces remained comparable between the 1993-2002 and the 2003-2012 ICUs (Figure 14). The most preferred location for common family waiting spaces was immediately outside the unit (60\% in the 1993-2002 ICUs vs. 50\% in the 2003-2012 ICUs). This was followed by the option that included family spaces both inside and immediately outside the unit (20\% in the 1993-2002 ICUs vs. 30\% in the 2003-2012 ICUs). The other less used options were family spaces within the unit only (13.33\% in the 1993-2002 ICUs vs. $10 \%$ in the 2003-2012 ICUs); family spaces away from the unit (6.667\% in the 1993-2002 ICUs vs. $0 \%$ in the $2003-2012$ ICUs); and 
family spaces both inside and away from the unit (0\% in the 1993-2002 ICUs vs. 10\% in the 2003-2012 ICUs). The finding that in most best-practice example ICUs the common family waiting spaces were outside the unit would indicate that the location of these spaces was still not considered as an important factor contributing to better family integration

\section{Family areas in the patient room}

Another factor contributing significantly to family integration with critical care is a dedicated family space within the patient room. Families are able to provide most support when present with the patient in the room [7]. Yet, the recommendations for families in the patient room of the FGI Guidelines are minimal: "Private patient rooms shall be sized to allow for a minimum of two seated visitors without interfering with providers’ access to the patient and equipment.” [2:100]

Concerning family spaces in the patient room, significant differences are observed between the bestpractice example ICUs of the 1993-2002 and the 2003-2012 decade (Figure 15). Only 13.33\% of the 1993-2002 ICUs, as opposed to 70\% of the 2003-2012 ICUs, had dedicated family space in the patient room. Conversely, $86.67 \%$ of the $1993-2002$ ICUs, as opposed to $30 \%$ of the $2003-2012$ ICUs, did not have dedicated family space in the patient room. The findings indicate a positive trend among the best practice example ICUs in terms of family integration with critical care. However, it is necessary to consider many architectural implications of having a dedicated family space in the patient room. First, a dedicated family space requires larger patient rooms, which may reduce the total number beds in the unit. Second, with a dedicated family space there may also be a need for toilet, storage space, internet, and TV within the room. Otherwise, families would frequently move in and out of the patient room contributing to noise and crowding within the unit. Third, a dedicated family space in the patient room does not diminish the need for a common family waiting space elsewhere. When families are asked to step outside by the staff, they need spaces to go to. Finally, the environmental needs of the patients and families are generally different, requiring additional environmental intervention within the patient room.

\section{SUMMARY AND CONCLUSION}

This study reviewed some of the physical design features of the award-winning adult ICUs built between 1993 and 2012, and compared the 1993-2002 ICUs with the 2003-2012 ICUs using these features. Based on the comparison, the study made the following observations regarding the overall design issues: 


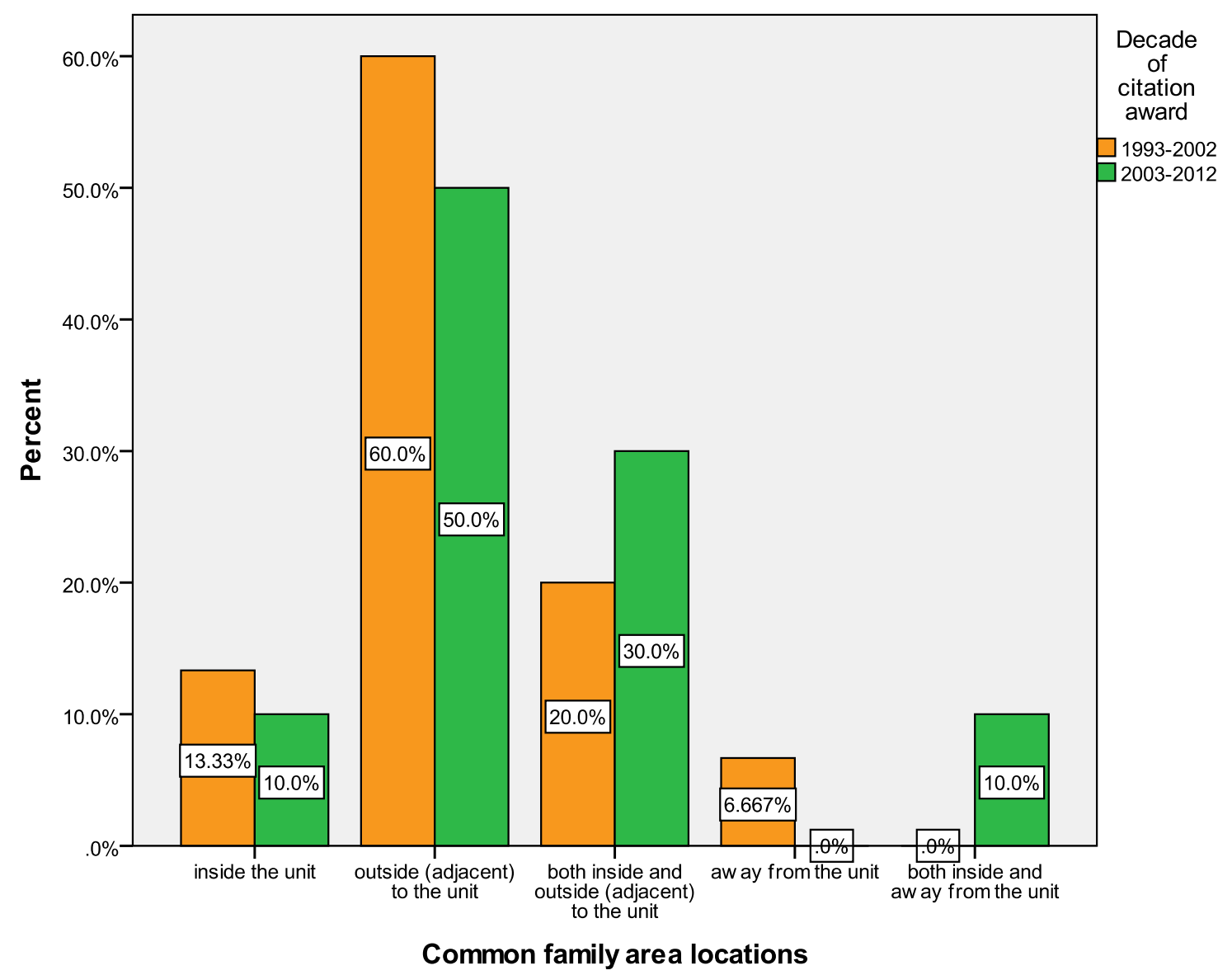

Figure 14: Common family waiting space locations by decade.

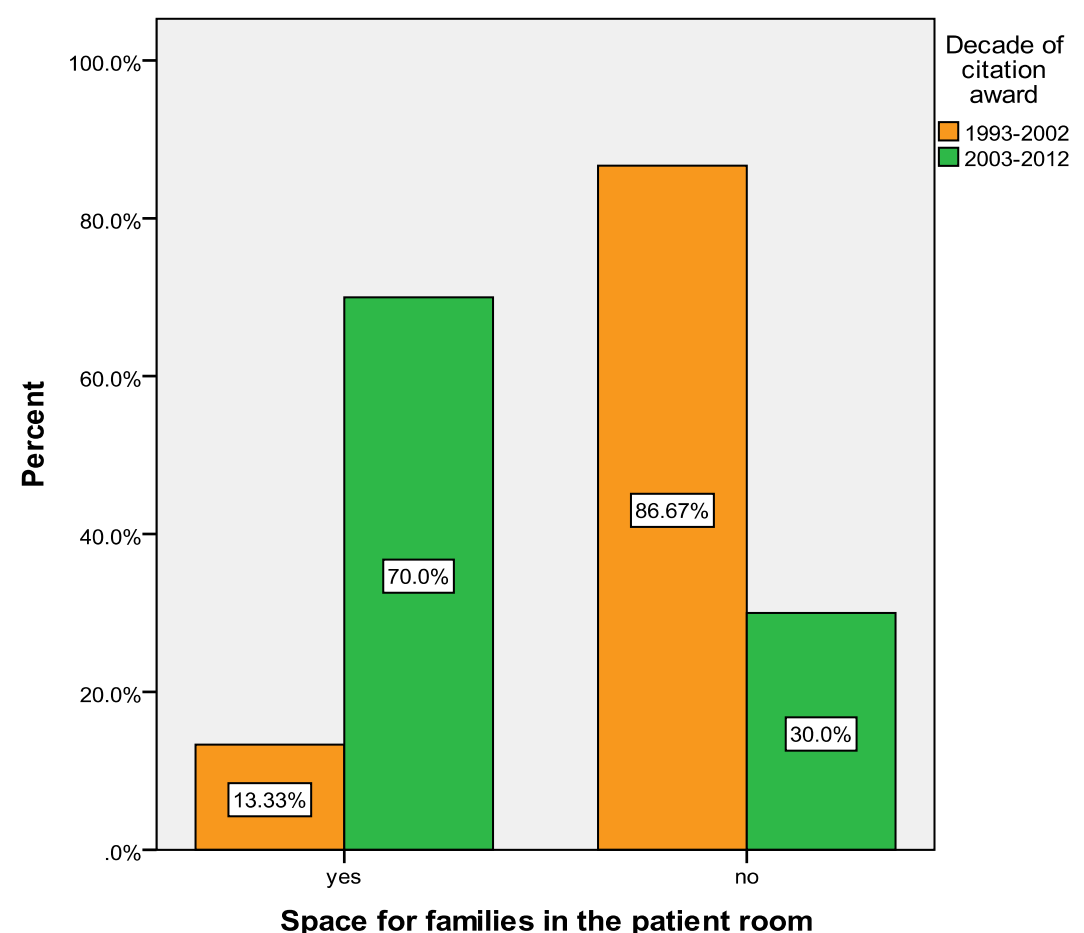

Figure 15: Family space in the patient room by decade. 
1) The percentage of renovated units declined and that of new units increased during the second decade;

2) The percentage of mixed-specialty units declined and that of single-specialty units increased during the second decade;

3) The racetrack type layout remained the most popular layout type during both the decades;

4) The average unit size in terms of the number of beds increased remarkably during the second decade; and

5) The ICUs with more beds generally had larger gross area.

Regarding the patient room design, the study made the following observations:

1) The average size of a typical patient room was 266.5 square feet during the second decade. This was16 square feet bigger than the average size of a typical patient room during the first decade;

2) Larger units with more beds had smaller areas for patient rooms;

3) The private patient room was equally important during both the decades;

4) The average number of isolation rooms per ICU increased during the second decade;

5) There was a decrease in the use of power columns and an increase in the use of booms for life support systems and medical utilities during the second decade;

6) The percentage of floor-mounted toilet with privacy curtain increased during the second decade;

7) The full-length sliding glass breakaway door was the most frequently used patient room door during both the decades;

8) Access to natural light and/or outside view from the patient room were considered to be important during both the decades;

9) The location of hand-washing sinks inside the patient room was the most preferred option during both the decades; and

10) Though many ICUs did not put the sinks near the entrance to the patient rooms as recommended by the Guidelines, the near end of the footwall of the patient room was still the most preferred location for hand-washing sinks during both the decades.

Regarding the staff work area and service area layout, the study made the following observations:

1) For the staff work area layout, while a configuration of observation stations was more common in the ICUs of the first decade, a configuration of substations and distributed observation stations was more common in the ICUs of the second decade;

2) Fewer variations in the configuration of staff work area were observed during the second decade; 
3) The location immediately next to the patient room remained most popular option for charting and documentation in both the decades; and

4) Sixty percent of the ICUs of the first decade used a centralized service area surrounded by nurse stations, but none of the second decade ICUs used this configuration of service area layout.

Regarding family areas, the study made the following observations:

1) All ICUs of both the decades had designated common family waiting spaces;

2) The most preferred location for common family waiting spaces was immediately outside the unit during both the decades; and

3) Only $13.33 \%$ of the $1993-2002$ ICUs, as opposed to $70 \%$ of the $2003-2012$ ICUs, had dedicated family space in the patient room.

In general, the study found that the award-winning ICUs of both the decades used several design features that were associated with positive outcomes in research studies. Among these evidence-based features were patient rooms that far exceeded the size recommended by the FGI Guidelines; mostly private patient rooms in all ICUs; many isolation rooms per ICU; more use of booms and power columns than other available configurations for life support systems and medical utilities; more use of full-length sliding glass breakaway doors than the other available door types for patient rooms; access to natural light and outside view from most patient rooms; hand-washing sinks in patient rooms to improve hand-washing compliance; charting locations next to patient rooms to reduce staff walking and documentation errors; and common family waiting spaces in all ICUs.

The study also found that the use of the evidence-based design features intensified in the award-winning ICUs of the second decade. This intensification was indicated by more new constructions as opposed to renovations; more single-specialty units as opposed to mixed-specialty units; patient rooms even larger than those in the ICUs of the earlier decade; more isolation rooms per ICU; a decrease in the use of power columns and an increase in the use of booms for life support systems and medical utilities; an increase in the number of floor-mounted toilet with privacy curtain; and more units with dedicated family space in the patient room.

Additionally, the study found that the award-winning ICUs of both the decades also implemented some design features which had very little or no supporting research evidence. These features included the preference for a racetrack type layout; the use of floor-mounted toilet with privacy curtain in the patient room of many ICUs; complete or partial decentralization of staff work areas in many ICUs; and a 
centralized service area surrounded by nurse stations in many ICUs of the first decade, but a complete absence of this configuration in the ICUs of the second decade.

Further, the study found that the award-winning ICUs of both the decades used some design features that contradicted with the existing research evidence or commonsense. Among these were very large units with very large numbers of patient beds that could negatively affect ICU outcomes; many ICUs without hand-washing sinks near the entrance to the patient rooms as recommended by the Guidelines; and many ICUs with common family waiting spaces located outside the unit, thus restricting family access to patients and care providers.

Despite limitations, the award-winning ICUs of the last two decades were able to create optimal critical care environments that helped improve outcomes related to patients, staff and visitors $[11,16]$. As this study has shown, these award-winning ICUs could not have achieved their goals if they were designed following the available design standards and guidelines only. They used design innovations as much as evidence-based design for their success. Therefore, having a good knowledge of these award-winning ICUs may help those who contemplate designing an ICU. For many, the award-winning ICUs are not easily accessible since they are scattered all over the country. Though the publications of SCCM, ACCN and AIA/AAH helped make the knowledge of these award-winning ICUs somewhat accessible, lacking time and resources many are unable to draw any conclusions using the data presented in these publications. Consequently, they follow the available standards and the guidelines to design ICUs that do not provide optimal critical care environments.

By providing a description of the physical design features of the award-winning adult ICUs of the last two decades contained in the 2012 SCCM, ACCN and AIA/AAH publications, this study hopes to make the physical design knowledge of the award-winning ICUs more accessible. Equipped with the knowledge, it may be possible to make more informed design decisions. However, the findings of the study must not be considered as prescriptions for better design. The critical care practice in an ICU depends on the level of technology availability and integration, managerial practices, organizational culture and climate, and various design features affecting where, when, and how the care is provided in the unit. While each ICU should be designed for its specific needs, the message of this study is that these needs must not be framed within the limitations imposed by the regulatory guidelines and any available design standards. Designing an optimal critical care environment must be an intentional process, where evidence-based design features along with the findings of this study must be considered carefully in relation to requirements of the present needs of the unit and the changing scenarios over the unit's lifespan. 


\section{REFERENCES}

1. Rashid M. A decade of adult intensive care unit design: A study of the physical design features of the best-practice examples. Cit Care Nurs Q 2006; 29(4):282-311.

2. The Facility Guidelines Institute. Guidelines for Design and Construction of Health Care Facilities. Chicago, IL, The Facility Guidelines Institute; 2010.

3. Thompson DR, Hamilton DK, Cadenhead CD, et al. Guidelines for intensive care unit design. Crit Care Med. 2012; 40(5): 1586-1600.

4. Delvin AS, Arneill AB. Health care environments and patient outcomes: a review of the literature. Environ Behav 2003;35(5):665-694.

5. Hamilton D, Shepley M. Design for Critical Care: An Evidence-based Design Approach. Oxford, UK, Architectural Press/Elsevier; 2010.

6. Joseph A. The Impact of the Environment on Infections in Healthcare Facilities. Concord, CA: The Center for Health Design; 2006.

7. Rashid M. Environmental design for patient families in intensive care units. J Healthc Eng-Spec Issue Crit Care Intensive Care Unit 2010;1(3):367-397.

8. Rashid M, Zimring C. A review of the empirical literature on the relationships between indoor environment and stress in healthcare and office settings: problems and prospects of sharing evidence. Environ Behav 2008; 40(3):151-190.

9. Ulrich RS, Zimring $\mathrm{C}$, Zhu $\mathrm{X}$, et al. A review of the literature on evidence-based healthcare design, HERD - Healthcare Environment Research and Design Journal 2008;1(3):61-125.

10. Cadenhead C, Anderson D. Critical care unit design, the winners and future trends: An investigative study. World Health Design Journal 2009; 2:72-77.

11. Society of Critical Care Medicine (SCCM), American Association of Critical Care Nurses (AACN), and American Institute of Architects (AIA). Award Winning ICU Designs: How to build a better facility for patients and caregivers. Society of Critical Care Medicine; 2012.

12. Society of Critical Care Medicine. Guidelines for intensive care unit design. Crit Care Med 1995; 23:582-588.

13. Hamilton DK. Design for flexibility in critical care. New Horizons 1999;7:205-217.

14. Hamilton DK, ed. ICU 2010: ICU Design for the Future, a Critical Care Design Symposium. Houston: Center for Innovation in Health Facilities; 2000.

15. National Institute of Health (NIH). NIH Consensus Development Conference on critical care medicine. Crit Care Med 1983;11:466-469. 
16. Society of Critical Care Medicine (SCCM), American Association of Critical Care Nurses (AACN), and American Institute of Architects (AIA). ICU Design Award Booklet and Videos. Society of Critical Care Medicine; 2005.

17. Rashid M. Technology and the future of intensive care unit design. Cit Care Nurs Q 2011; 34(4): 332-360.

18. Bartley JM, Olmsted RN, Haas J: Current views of health care design and construction: Practical implications for safer, cleaner environments. Am J Infect Control 2010;38:S1-S12.

19. Carter CD, Barr BA. Infection control issues in construction and renovation. Infect Control Hosp Epidemiol. 1997;18(8):587-596.

20. Goodley JM, Clayton YM, Hay RJ. Environmental sampling for aspergilli during building construction on a hospital site. J Hosp Infect. 1994;26(1):27-35.

21. Iwen PC, Davis JC, Reed EC, Winfield BA, Hinrichs SH. Airborne fungal spore monitoring in a protective environment during hospital construction, and correlation with an outbreak of invasive aspergillosis. Infect Control Hosp Epidemiol. 1994;15(5):303-306.

22. Oren I, Haddad N, Finkelstein R, Rowe JM. Invasive pulmonary aspergillosis in neutropenic patients during hospital construction: Before and after chemoprophylaxis and institution of HEPA filters. American Journal of Hematology 2001; 66(4):257-262.

23. Shortell SM, Zimmerman JE, Rousseau DM, et al. The performance of intensive care units: Does good management make a difference? Medical Care 1994; 32 (5): 508-525.

24. James WP, Tatton-Brown W. Hospitals: Design and Development. London: The Architectural Press; 1986.

25. Shepley MM, Davies K. Nursing unit configuration and its relationship to noise and nurse walking behavior: An AIDS/ HIV unit case study. AIA Academy Journal 2003 [Retrieved 0n 04 August 2012 from http://www.aia.org/groups/aia/documents/pdf/aiab090850.pdf]

26. Sturdavant M. Intensive nursing service in circular and rectangular units. Hospitals-JAHA 1960;34: 46-48, 71-78.

27. Trites DK, Galbraith F D, Sturdavant M, Leckwart JF (1970). Influence of nursing-unit design on the activities and subjective feelings of nursing personnel. Environment \& Behavior 1970; 2(3):303-334.

28. Archibald LK, Manning ML, Bell LM, Banerjee S, Jarvis WR. Patient density, nurse-to-patient ratio and nosocomial infection risk in a pediatric cardiac intensive care unit. Pediatric Infectious Disease Journal 1997;16(11):1045-1048.

29. Borg MA. Bed occupancy and overcrowding as determinant factors in the incidence of MRSA infections within general ward settings. Journal of Hospital Infection 2003;54:316-318. 
30. Vincent JL, Bihari DJ, Suter PM, et al. The prevalence of nosocomial infection in intensive care units in Europe. JAMA 1995;274:639-644.

31. Cepeda JA, Whitehouse T, Cooper B, et al: Isolation of patients in single rooms or cohorts to reduce spread of MRSA in intensive-care units: Prospective two-centre study. Lancet 2005; 365:295-304.

32. Chaudhury H, Mahmood A, Valente M. Advantages and disadvantages of single versus multipleoccupancy rooms in acute care environments-A review and analysis of the literature. Environment and Behavior 2005:37(6):760-786.

33. Gabor JY, Cooper AB, Crombach SA, et al: Contribution of the intensive care unit environment to sleep disruption in mechanically ventilated patients and healthy subjects. Am J Respir Crit Care Med 2003;167:708-715.

34. Harris DD, Shepley MM, White RD, et al: The impact of single family room design on patients and caregivers: Executive summary. Journal of Perinatology 2006; 26:S38-S48.

35. Teltsch DY, Hanley J, Loo V, et al: Infection acquisition following intensive care unit room privatization. Arch Intern Med 2011;171:32-38.

36. Vonberg, R. P., \& Gastmeier, P. (2005). Isolation of infectious cystic fibrosis patients: Results of a systematic review. Infection Control and Hospital Epidemiology, 26(4), 401-409.

37. McManus AT, Mason AD, McManus WF, Pruitt BA. A decade of reduced gram-negative infections and mortality associated with improved isolation of burned patients. Archives of Surgery 1994; 129(12):1306-1309.

38. Passweg JR, Rowlings PA, Atkinson KA, Barrett AJ, Gale RP, Gratwohl A, et al. Influence of protective isolation on outcome of allogeneic bone marrow transplantation for leukemia. Bone Marrow Transplantation 1998;21(12):1231-1238.

39. Pati D, Evans J, Waggener L, et al: An exploratory examination of medical gas booms versus traditional headwalls in intensive care unit design. Crit Care Nurs Q 2008; 31:340-356

40. Malamou-Ladas H, O’Farrell S, Nash JQ, Tabaqchali S. Isolation of Clostridium difficile from patients and the environment of hospital wards. Journal of Clinical Pathology 1983; 36:88-92.

41. Burrington M. An alternative method for human waste disposal in critical care. In: Design for Critical Care: An Evidence-based Design Approach. Hamilton D, Shepley M (Eds). Oxford, UK, Architectural Press/Elsevier; 2010, pp 267-273.

42. Harrell JW, Miller B. Big challenge. Designing for the needs of bariatric patients. Health Facil Manage 2004; 17:34-38.

43. Benedetti F, Colombo C, Barbini B, Campori E, Smeraldi E. Morning sunlight reduces length of hospitalization in bipolar depression. Journal of Affective Disorders 2001; 62(3):221-223. 
44. Beauchemin KM, Hays P. Sunny hospital rooms expedite recovery from severe and refractory depressions. Journal of Affective Disorders 1996; 40(1-2): 49-51.

45. Diette GB, Lechtzin N, Haponik E, Devrotes A, Rubin HR. Distraction therapy with nature sights and sounds reduces pain during flexible bronchoscopy: A complementary approach to routine analgesia. Chest 2003;123(3):941-948.

46. Federman EJ, Drebing CE, Boisvert C, Penk W. Relationship between climate and psychiatric inpatient length of stay in veterans' health administration hospitals. The American Journal of Psychiatry 2000;157(10):1669.

47. Keep PJ: Stimulus deprivation in windowless rooms. Anaesthesia 1977; 32:598-602.

48. Ulrich RS. View through a window may influence recovery from surgery. Science 1984; 224:420421.

49. Walch JM, Rabin BS, Day R, Williams JN, Choi K, Kang JD. The effect of sunlight on postoperative analgesic medication usage: A prospective study of patients undergoing spinal surgery. Psychosomatic Medicine 2005; 67:156-163.

50. Bischoff WE, Reynolds TM, Sessler CN, Edmond MB, Wenzel RP. Hand washing compliance by health care workers-The impact of introducing an accessible, alcohol- based hand antiseptic. Archives of Internal Medicine 2000;160(7):1017-1021.

51. Boyce JM, Pittet D. Guideline for hand hygiene in health-care settings-Recommendations of the Healthcare Infection Control Practices Advisory Committee and the HICPAC/ SHEA/APIC/IDSA Hand Hygiene Task Force. American Journal of Infection Control 2002; 30(8):s1-s46.

52. Creedon SA. Healthcare workers' hand decontamination practices: Compliance with recommended guidelines. Journal of Advanced Nursing 2005;51(3):208-216.

53. Kaplan LM, McGuckin M. Increasing handwashing compliance with more accessible sinks. Infect Control 1986;7:408-410.

54. Randle J, Clarke M, Storr J. Hand hygiene compliance in healthcare workers. Journal of Hospital Infection 2006; 64(3):205-209.

55. Zaragoza M, Sallés M, Gomez J, et al. Handwashing with soap or alcoholic solutions? A randomized clinical trial of its effectiveness. Am J Infect Control 1999;27:258-261.

56. Leaf DE, Homel P, Factor PH. Relationship between ICU design and mortality. Chest 2010; 137:1022-1027.

57. Durbin CG Jr. Team model: Advocating for the optimal method of care delivery in the intensive care unit. Crit Care Med 2006;34:S12-S17.

58. Busby A, Gilchrist B. The role of the nurse in the medical ward round. J Adv Nurs 1992;17:339-346. 
59. Sisterhen LL, Blaszak RT, Woods MB, et al. Defining family-centered rounds. Teach Learn Med 2007; 19:319-322.

60. Gurses AP, Xiao Y. A systematic review of the literature on multidisciplinary rounds to design information technology. J Am Med Inform Assoc 2006; 13:267-276.

61. Kim MM, Barnato AE, Angus DC, et al. The effect of multidisciplinary care teams on intensive care unit mortality. Arch Intern Med 2010; 170:369-376.

62. Gurasio-Howard L, Malloch K. Centralized and decentralized nurse station design: an examination of caregiver communication, work activities, and technology. HERD-Health Environment Research \& Design Journal 2007;1(1):44-57.

63. Zborowsky T, Bunker-Hellmich L, Morelli A, O'Neill M. Centralized vs. decentralized nursing stations: Effects on nurses' functional use of space and work environment. HERD-Health Environments Research \& Design Journal 2010: 3(4):19-42. 